\title{
Neuroimaging Paradigms to Identify Patients for Reperfusion Therapy in Stroke of Unknown Onset
}

\author{
Mark R. Etherton ${ }^{1}$, Andrew D. Barreto ${ }^{2}$, Lee H. Schwamm ${ }^{1}$ and Ona $W^{1,3 *}$ \\ 'Department of Neurology, JPK Stroke Research Center, Massachusetts General Hospital (MGH), Harvard Medical School, \\ Boston, MA, United States, ${ }^{2}$ Stroke Division, Department of Neurology, McGovern Medical School at the University of Texas \\ Health Science Center at Houston, Houston, TX, United States, ${ }^{3}$ Department of Radiology, Athinoula A. Martinos Center for \\ Biomedical Imaging, Massachusetts General Hospital (MGH), Charlestown, MA, United States
}

OPEN ACCESS

Edited by:

Nishant K. Mishra,

Tulane University,

United States

Reviewed by:

Richard Zweifler,

Ochsner Health System,

United States

Vincent Thijs,

Florey Institute of Neuroscience and Mental Health, Australia

*Correspondence:

Ona Wu

ona@nmr.mgh.harvard.edu

Specialty section: This article was submitted to Stroke,

a section of the journal

Frontiers in Neurology

Received: 01 March 2018 Accepted: 25 April 2018

Published: 15 May 2018

Citation:

Etherton MR, Barreto $A D$, Schwamm LH and Wu O (2018) Neuroimaging Paradigms to Identify Patients for Reperfusion Therapy in Stroke of Unknown Onset.

Front. Neurol. 9:327. doi: 10.3389/fneur.2018.00327
Despite the proven efficacy of intravenous alteplase or endovascular thrombectomy for the treatment of patients with acute ischemic stroke, only a minority receive these treatments. This low treatment rate is due in large part to delay in hospital arrival or uncertainty as to the exact time of onset of ischemic stroke, which renders patients outside the current guideline-recommended window of eligibility for receiving these therapeutics. However, recent pivotal clinical trials of late-window thrombectomy now force us to rethink the value of a simplistic chronological formulation that "time is brain." We must recognize a more nuanced concept that the rate of tissue death as a function of time is not invariant, that still salvageable tissue at risk of infarction may be present up to $24 \mathrm{~h}$ after last-known well, and that those patients may strongly benefit from reperfusion. Multiple studies have sought to address this clinical dilemma using neuroimaging methods to identify a radiographic time-stamp of stroke onset or evidence of salvageable ischemic tissue and thereby increase the number of patients eligible for reperfusion therapies. In this review, we provide a critical analysis of the current state of neuroimaging techniques to select patients with unwitnessed stroke for revascularization therapies and speculate on the future direction of this clinically relevant area of stroke research.

Keywords: ischemic stroke, neuroimaging, reperfusion therapy, unwitnessed stroke, wake-up stroke

\section{INTRODUCTION}

The treatment options for acute ischemic stroke are currently predicated on a confirmed last-known well (LKW) and the time-period from LKW to hospital evaluation. For those patients that present and start treatment within $4.5 \mathrm{~h}$ from LKW, administration of intravenous recombinant tissue plasminogen activator (IV tPA) reduces disability after acute ischemic stroke $(1,2)$. Likewise, those with large-vessel occlusions (LVO) of the anterior circulation who can start treatment within $6 \mathrm{~h}$ of LKW, endovascular thrombectomy (EVT) is a powerful therapy for improving long-term functional outcomes (3-6). Recently, two pivotal trials $(7,8)$ now extend that window up to $24 \mathrm{~h}$ in highly selected patients with imaging demonstrating small infarct core lesions and salvageable tissue by imaging or clinical measures. Unfortunately, these efficacious acute therapies are limited both by the relatively narrow treatment window for either IV tPA or EVT, and the relatively infrequent (5.7-12.8\%) occurrence of LVO accompanied by a favorable tissue signature in the later time windows (9). Because of this, many ischemic stroke patients are not eligible for these therapies. While the rates of thrombolysis 
are increasing in the United States, conservative estimates in 2009 suggested that only 3-5\% of all stroke patients receive treatment with IV tPA (10). One reason for its underuse may be the strict time restrictions from LKW (11). Exacerbating this issue, current estimates suggest that $31-36 \%$ of acute ischemic stroke patients have stroke of unknown symptom onset (SUSO) but do have an LKW time $(12,13)$, with a large proportion of these with deficits upon awakening, or "wake-up strokes" (WUS) (14-16). These patients with SUSO highlight the challenge of relying on a human witness of symptom onset, which greatly limits the opportunities for reperfusion therapy.

For these reasons, there is much interest in developing novel approaches to expand patient eligibility for revascularization therapies (e.g., IV tPA or EVT) to SUSO patients. Given the potentially large proportion of ischemic stroke patients that these populations represent, identifying approaches to discern which patients with SUSO may still safely benefit from reperfusion therapy holds enormous clinical and epidemiological ramifications. The interest in this question is exemplified by the increasing number of publications on this topic (Figure 1). Advanced neuroimaging has been applied to patients with SUSO based on two principles: (1) to substitute for the human witness of stroke onset by providing radiographic surrogates for stroke duration or (2) to identify patients with sufficient salvageable tissue at risk of dying to make the potential benefit of revascularization therapy worth the risk and considerable resource utilization of "late" intervention. The DAWN (DWI or CTP Assessment with Clinical Mismatch in the Triage of Wake-Up and Late Presenting Strokes Undergoing Neurointervention with Trevo) and DEFUSE 3 (Endovascular

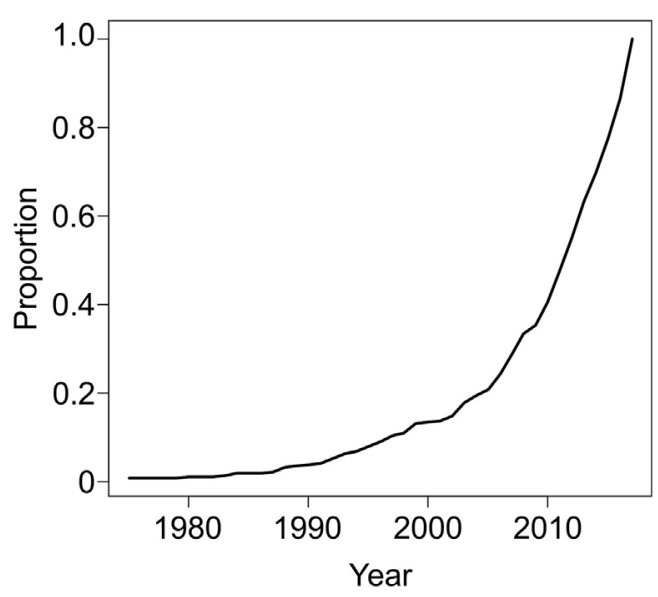

FIGURE 1 | PUBMED search on January 11, 2018 (294 hits, 112 relevant) using the following terms: "stroke"[Title/Abstract] AND ("unwitnessed"[Title/ Abstract] OR "unclear onset"[Title/Abstract] OR "unclear-onset"[Title/ Abstract] OR "wake"[Title/Abstract] OR "wakeup"[Title/Abstract] OR awake* [Title/Abstract] OR "unknown onset"[Title/Abstract] OR "unknownonset"[Title/Abstract]) AND ("trial"[Title/Abstract] OR therap* [Title/Abstract] OR treat ${ }^{\star}$ [Title/Abstract] OR thrombolysis [Title/Abstract]) NOT

("review"[Publication Type] OR "review literature as topic"[MeSH Terms]) NOT ("animals"[MeSH Terms:noexp] OR animal[All Fields]) demonstrate increasing interest in the treatment of patients with unknown symptom onset restricted up to December 31, 2017.
Therapy Following Imaging Evaluation for Ischemic Stroke) randomized clinical trials (RCTs) used different approaches to identify these potential candidates for EVT, and their success has much to teach us about the patients who can still benefit from late-window reperfusion. In this review, we will discuss the current evidence supporting the use of neuroimaging approaches for evaluation of patients with SUSO to identify populations that may benefit from delayed reperfusion interventions.

\section{WAKE-UP STROKE AS A DISTINCT CLASS OF SUSO}

Wake-up strokes are hypothesized to represent a unique entity within SUSO as it is difficult to delineate the timing of stroke onset including the possibility that it may have occurred on awakening (17). Many have posited that there is a circadian variation in the frequency of ischemic stroke with most strokes occurring between 6:00 AM and 12:00 PM (15, 18-22). A metaanalysis of 8,250 patients with ischemic stroke demonstrated a $55 \%$ increased risk between $6 \mathrm{AM}$ and noon (22). The diurnal variation in ischemic stroke is also thought to have contributions from morning increases in blood pressure, platelet aggregation, and prothrombotic factors (23-25). These observations have led many to speculate on circadian-related mechanisms underlying WUS, similar to those reported for myocardial infarction, and that WUS patients may have stroke onset contiguous with wakening. Multiple studies have in fact shown comparable presentation and outcomes in WUS patients vs. those with witnessed stroke onset $(14,19,26,27)$. One large study that investigated the cohort of WUS patients enrolled in the International Stroke Trial found that WUS patients, despite presenting with milder symptoms, had similar mortality rates and likelihood of poor outcome as patients with stroke onset while awake (28).

On the other hand, non-wake-up SUSO patients appear to represent a different clinical population than WUS SUSO patients. One study demonstrated that non-wake-up SUSO patients differ clinically from wake-up SUSO patients (more severe symptoms, faster arrival time from symptom discovery). Non-wake-up SUSO patients also appear to have worse prognosis than either WUS or witnessed stroke patients and the proportion of patients with non-wake-up SUSO may be increasing $(29,30)$. These findings suggest that both wake-up and non-wake-up SUSO patients represent a vulnerable subpopulation of AIS patients in need of developing new management paradigms for expanding reperfusion therapy eligibility. With the success of the late-window EVT trials $(7,8)$ and new guideline recommendations (11), the clinical focus should shift to expanding therapies for late-window patients without LVO or who lack rapid access to advanced neuroimaging and EVT.

\section{SUSO VS. STROKE OF KNOWN SYMPTOM ONSET (SKSO)}

\section{Computed Tomography (CT)}

There have been several CT-based approaches to characterizing SUSO patients as compared with their witnessed stroke 
counterparts. Multiple studies have demonstrated no significant difference in the extent of ischemic changes on the admission CT between WUS SUSO and SKSO patients (31-33) using the Alberta stroke program early CT score (ASPECTS) scale, which is a CT-based assessment of early ischemic changes in the middle cerebral artery (MCA) territory (34). Further supporting the argument that WUS SUSO patients may represent a distinct population, a study comparing cardioembolic SKSO (46 patients), non-WUS SUSO (18 patients), and WUS (17 patients) observed no significant difference between the SKSO and WUS groups in the number of patients presenting with a normal head CT (30 vs. $22 \%, P=0.76$ ) or hypodense area ( 0 vs. $11 \%, P=0.069)(26)$. However, no patients in the non-WUS SUSO group had a normal head CT and $56 \%$ had a visualized hypodense area $(P<0.001)$ (26). Another study used CT perfusion (CTP) to characterize 420 stroke patients with known symptom onset, 131 patients with WUS, and 125 with non-wake-up SUSO (35). The non-wake-up SUSO group had larger lesion volumes on CT-angiogram source images compared with the other two groups $\left(46.6-\mathrm{cm}^{3} \mathrm{SUSO}\right.$ vs. $14.3-\mathrm{cm}^{3}$ SKSO vs. $14.4-\mathrm{cm}^{3}$ WUS, $P=0.04$ ) but no difference in the frequency of CTP mismatch or presence of LVO (35).

\section{Magnetic Resonance Imaging (MRI)}

Magnetic resonance imaging-based approaches to identifying WUS patients who may benefit from reperfusion have also been performed. A retrospective study of 364 stroke patients, which included 100 patients with WUS, showed no differences in median stroke severity, as assessed by National Institutes of Health Stroke Scale (NIHSS) score (SKSO 7 vs. WUS 5; $P=0.06$ ), age, or gender between the WUS and known stroke onset groups (14). Notably, while time from stroke onset was shorter in the known stroke onset group ( 6.0 vs. $13.3 \mathrm{~h}, P<0.001)$, there was no significant difference in time from symptom detection (6.0 vs. $5.9 \mathrm{~h}, P=0.83$ ) (14). Of those patients imaged within $3 \mathrm{~h}$ of symptom discovery $(N=69)$, there was no difference in either the diffusion-weighted imaging (DWI: $26.8-\mathrm{cm}^{3}$ SKSO vs. 19.6$\mathrm{cm}^{3}$ WUS) or perfusion-weighted imaging (PWI) lesion volumes (107.7- $\mathrm{cm}^{3}$ SKSO vs. $82.7-\mathrm{cm}^{3}$ WUS) (14).

Imaging findings of non-WUS SUSO patients have also been characterized with MRI, though not to the same extent as the WUS cohort. One retrospective study found that non-WUS SUSO patients $(N=104)$ were more likely to have DWI and FLAIR (fluid-attenuated inversion recovery) mismatch (non-WUS SUSO: 35.1 vs. WUS: $21.9 \% ; P=0.02)$, and DWI-PWI mismatch $(P=0.001)$ than WUS $(N=172)(13)$. However, a prospective study of SUSO patients found that the frequency of DWI-FLAIR mismatch (DFM), defined as a visible acute lesion on DWI but no obvious parenchymal hyperintensity in the corresponding region of the FLAIR sequence, was similar in both the WUS and non-WUS SUSO groups (43.7 vs. $48.7 \% ; P=0.3$ ) (30).

\section{NEUROIMAGING TIME-STAMP OF STROKE DURATION}

The aforementioned studies suggest that SUSO patients present with similar clinical and imaging findings as their SKSO counterparts, as long as they are evaluated within a comparable time frame from stroke onset. This observation has prompted the utilization of imaging as a potential surrogate witness of onset when no human witness is available. Before using an imagingbased witness, it is critical to determine the key imaging features that can discriminate between patients within the therapeutic time window and those who are outside the window. Imagingsurrogates for stroke duration have been primarily based on MRI, specifically, the DWI (or apparent diffusion coefficient, ADC) and FLAIR sequences. Several clinical studies of acute ischemic stroke patients have strengthened the argument that patients with abnormal ADC and normal FLAIR are likely within 3-4 h of stroke onset and that assessing for DFM may be associated with stroke duration (Figure 2) (36-39).

In one study of AIS patients with brain MRI obtained within $12 \mathrm{~h}$ of stroke onset, the median time from known symptom onset was significantly longer in FLAIR-positive vs. FLAIRnegative patients (189 min, interquartile range $110-369$ vs. 103 min, interquartile range $75-183 \mathrm{~min} ; P=0.011$ ) (39). Moreover, in patients with infarct volume exceeding $0.5-\mathrm{cm}^{3}$ on DWI, FLAIR-negative MRI showed $80 \%$ specificity and $51 \%$ sensitivity for imaging within $3 \mathrm{~h}$ of stroke onset (39). However, the authors observed no significant correlation between the signal intensity ratio and time from stroke onset. In contrast, another study showed a strong positive correlation between the time from stroke onset and the intensity of the FLAIR signal change relative to its contralateral homologous region (40). These findings support the idea that with longer stroke duration, the likelihood of visible FLAIR abnormalities increases. This allows for the hypothesis that patients with visible changes on DWI (or ADC) but normal FLAIR will likely have relatively recent stroke onset.

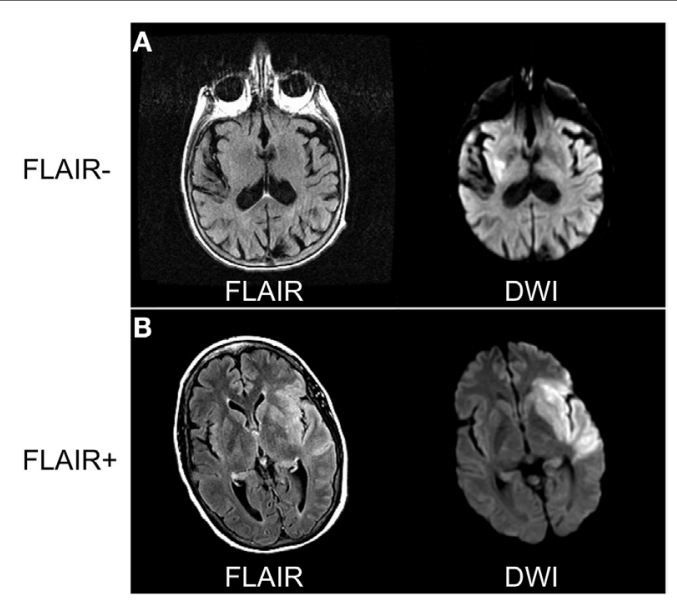

FIGURE 2 | Comparing diffusion-weighted imaging (DWI) and FLAIR sequences to determine radiographic time of stroke onset. (A) Eighty-oneyear-old woman awoke with dysarthria and right-sided weakness. Magnetic resonance imaging (MRI) performed $8 \mathrm{~h}$ from last-known well (LKW) shows signal abnormality in DWI but not FLAIR sequences. (B) Sixty-three-year-old woman developed sudden onset right-sided weakness with confirmed LKW. MRI performed $5 \mathrm{~h}$ from LKW shows signal abnormality on both DWI and FLAIR sequences consistent with stroke onset $>4.5 \mathrm{~h}$. Data analysis for figure was created under approval of local ethics committee. 
Several studies have strengthened the idea that DFM can inform on stroke duration. One retrospective investigation of 120 patients with AIS within $6 \mathrm{~h}$ of known symptom onset showed that presence of DFM identified patients with stroke onsets within 3 h or less with $93 \%$ specificity and $48 \%$ sensitivity (36). Importantly, $98.3 \%$ of the study population had confirmed arterial occlusions. Those patients that were FLAIR-positive were imaged significantly later than the FLAIR-negative group (180 vs. 120 min, $P<0.001$ ) (36). In a retrospective, multicenter followup to this study involving 543 patients with AIS, DFM identified with $78 \%$ specificity and $62 \%$ sensitivity patients within $4.5 \mathrm{~h}$ and $87 \%$ specificity and $56 \%$ sensitivity patients within $6 \mathrm{~h}$ from stroke onset (41). Two additional studies demonstrated that scans with DFM were highly specific (71-80\%) for identifying patients within $3 \mathrm{~h}$ of stroke onset $(37,38)$. Lastly, another study demonstrated that the presence of DFM on 3T MRI also has a high positive predictive value (88\%) for the stroke occurring within $4.5 \mathrm{~h}$; however, $44.5 \%$ of this population had positive FLAIR within $4.5 \mathrm{~h}$ of stroke onset and would not considered DFM (42). These results suggest that on 3T MRI, the presence of DFM can identify patients with stroke onset $<4.5 \mathrm{~h}$ with high specificity but that a significant percentage of patients in the $<4.5 \mathrm{~h}$ window can have positive FLAIR signals. Taken together, these findings demonstrate that MRI can, with high specificity, identify patients in the hyperacute (i.e., <3-4.5 h) phases of AIS based on DFM.

Using neuroimaging to serve as a radiographic biomarker of stroke onset holds much promise for potentially expanding eligibility for thrombolytic therapy. One analysis of WUS patients with DFM suggested that an additional $30 \%$ would be eligible for treatment with IV tPA (43). As such, several clinical trials have asked the question of whether DFM can be safely and efficaciously used for the treatment of SUSO patients with thrombolytics.

\section{MOVING BEYOND THE CLOCK: SHIFTING THE PARADIGM FROM "TIME IS BRAIN" TO "IMAGING IS BRAIN"}

Complementary to the notion that imaging can serve as a surrogate for stroke duration is that imaging can directly measure the degree of injury the brain has already experienced from the ischemic event. While the duration of time since symptom onset is highly correlated with progression of brain tissue injury, there is tremendous between-subject variability as to the rate of tissue death in the face of a heterogeneous degree of ischemia. While one can calculate an average rate of neuronal death in AIS due to LVO (1.9 million neurons/min) (44), recent data confirm that many patients still have viable tissue well beyond $6 \mathrm{~h}$ after symptom onset. Early animal models of ischemic stroke have supported the hypothesis that mismatch between the DWI and T2-weighted signals reflect histologically salvageable tissue, which happen to also be associated with short stroke durations (45). This has prompted different neuroimaging approaches to quantify or characterize salvageable tissue as a radiographic surrogate of patients likely to benefit from reperfusion therapies. The importance of using neuroimaging to identify patients likely to benefit from reperfusion therapies is exemplified, in part, by the results of the International Management of Stroke III RCT (46), which enrolled $53.4 \%$ of subjects with no baseline CTA to confirm LVO and $45 \%$ of subjects with ASPECTS $<8$, and failed to show benefit of EVT, as compared with the positive EVT trials of 2015, which used stricter criteria for identifying LVO patients with small ischemic cores $(4,5,47,48)$. However, this trial used mostly first- and second-generation devices and it is unknown what the impact would have been if stent retrievers had been used. In the next sections, we will review the different imagingbased approaches to quantify viable tissue in patients with AIS independent from LKW.

\section{Infarct Core-Perfusion Mismatch}

One approach has been to apply MRI or CT-based imaging techniques to quantify infarct core-perfusion mismatch as an indicator of salvageable tissue. While these two modalities measure core in very different ways, they both seek to differentiate irreparably injured tissue from tissue that is potentially recoverable.

\section{MRI-Based Perfusion-Diffusion Mismatch}

Magnetic resonance imaging-based techniques are one method that has been utilized to quantify salvageable tissue. Tissue that is abnormal on DWI due to restricted diffusion typically represents tissue that has the highest probability of infarction, with tissue salvage rare even with reperfusion (49), and therefore typically referred to as the infarcted "core" (50). PWIs, in particular gadolinium-arrival time measures such as $T_{\max }$ [time to peak value of deconvolved residue function (51)], have been used to identify tissue that is at risk for ischemic infarction but has not yet irreversibly committed to cell death $(45,51-56)$. These observations represent the foundations of utilizing PWI-DWI mismatch to identify salvageable tissue as an alternative triage approach for SUSO patients (Figure 3).

Investigating this hypothesis, the Diffusion and Perfusion Imaging Evaluation for Understanding Stroke Evolution (DEFUSE) study was an observational study of IV tPA-treated patients for which target perfusion-diffusion mismatch was defined as mismatch volume (PWI-DWI) $>10 \mathrm{~cm}^{3}$ or mismatch ratio $(\mathrm{PWI} / \mathrm{DWI})>1.2$. PWI lesion was defined as tissue exhibiting $T_{\max } \geq 2 \mathrm{~s}$. MRI was obtained before and 3-6 h after IV tPA treatment. A total of $68 \%$ of the study population had a confirmed partial or complete arterial occlusion of the internal carotid artery (ICA), MCA, or posterior cerebral artery (PCA). DEFUSE enrolled 74 patients and found that $56 \%(N=18)$ with perfusion-diffusion mismatch and early reperfusion had a favorable outcome (defined as improvement of NIHSS between baseline and 30 days of 8 points or more or score of $0-1$ at day 30) (57).

In a subsequent prospective cohort study, DEFUSE 2 (58), the same approach was applied to patients with LVO of the anterior circulation (defined as intracranial ICA or first segment of the MCA) treated with EVT within $12 \mathrm{~h}$ of LKW. The target mismatch profile was notably modified from that used in DEFUSE; mismatch ratio $>1.8\left(T_{\max }>6\right.$-s volume/DWI volume) and an absolute difference $\geq 15 \mathrm{~cm}^{3}$, DWI lesion volume $<70$ $\mathrm{cm}^{3}$, and $T_{\max }>10-\mathrm{s}$ volume $<100 \mathrm{~cm}^{3}$. In the 78 patients with target mismatch, the adjusted odds ratio for favorable outcome (same definition as DEFUSE) with reperfusion was 8.8 (95\% 


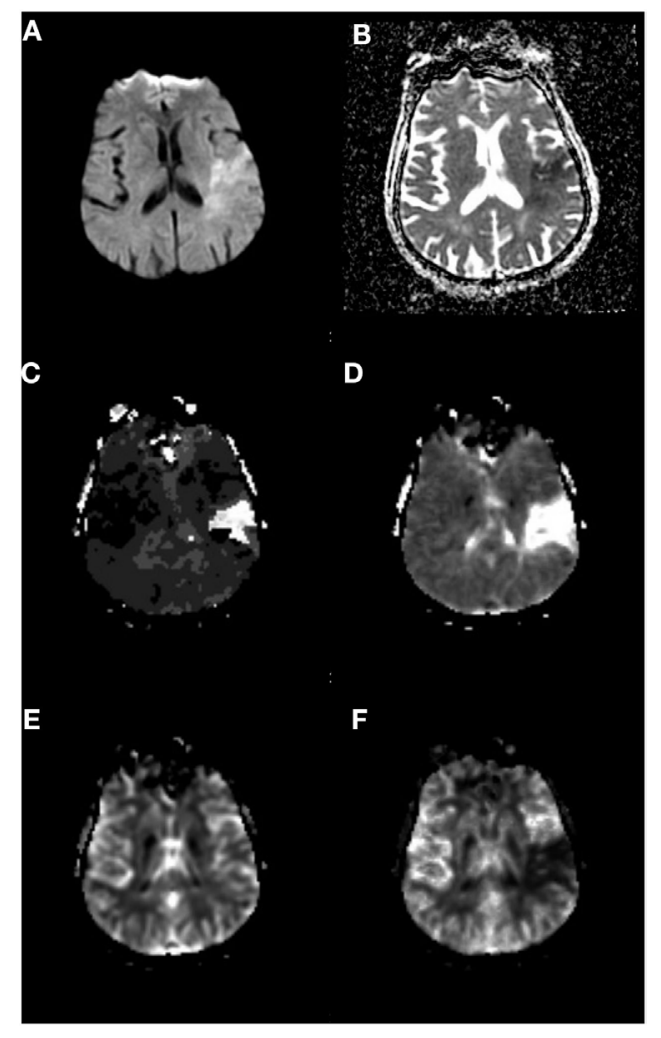

FIGURE 3 | Perfusion-Diffusion mismatch to identify salvageable tissue. (A) Diffusion-weighted imaging and (B) apparent diffusion coefficient sequences showing mismatch of ischemic core to a greater volume of hypoperfused tissue on (C) $T_{\max }$ and (D) mean transit time sequences. (E) Cerebral blood volume and (F) cerebral blood flow sequences. Data analysis for figure was created under approval of local ethics committee.

CI 2.7-29) compared with 0.2 (95\% CI 0-1.6) in the no target mismatch group $(P=0.003)$. Moreover, in the target mismatch group, reperfusion was associated with decreased infarct growth at 5 days ( 30 vs. $73 \mathrm{~cm}^{3}, P=0.01$ ). It should be noted that both DEFUSE and DEFUSE 2 were observational studies with treatment decisions made independent of imaging findings, which introduce selection bias; once enrolled, all patients received IV tPA or endovascular intervention.

\section{CT-Based Infarct Core-Perfusion Mismatch}

Due to the relative insensitivity of non-contrast CT for detecting early ischemic changes (59), alternative methods of defining core lesion volume are needed for CT-based screening methods. Thresholded relative cerebral blood flow ( $\mathrm{rCBF}$ ) maps have been used to approximate core lesion volumes, though, unlike DWI, they do not measure tissue infarction (Figure 4). Rather they are based on the probabilistic association that areas with substantive hypoperfusion are highly likely to progress to infarction despite reperfusion. These estimates can be highly variable at two extreme conditions: (1) patients with LVO stroke imaged early at stroke onset exhibiting large $\mathrm{rCBF}$ lesion volumes that grossly overestimate final infarct volume in settings of early reperfusion, and (2) patients with many hours of occlusion imaged after late

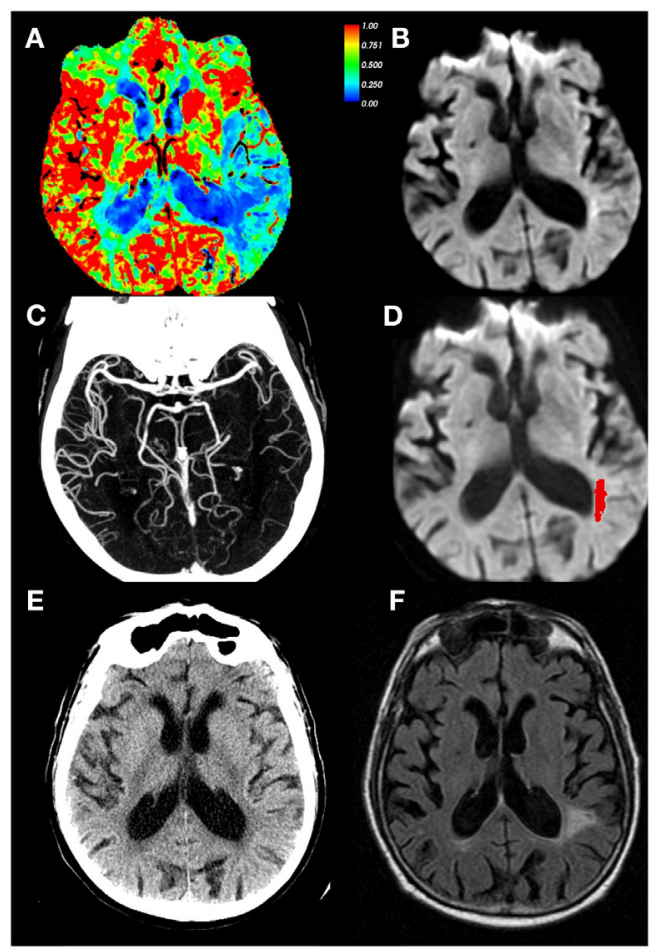

FIGURE 4 | CT perfusion (CTP) cerebral blood flow (CBF) maps do not correspond with infarct core. Eighty-four-year-old male with left middle cerebral artery (MCA) stroke with dense distal M2 occlusion presenting with initial National Institutes of Health Stroke Scale (NIHSS) of 9. By the time of the admission, NIHSS was 2 and patient did not receive IV tPA or endovascular treatment. The CTA CT perfusion (CTP) was acquired at $4.9 \mathrm{~h}$ from last-known well (LKW), magnetic resonance imaging was performed 19 min after the CTP. (A) CBF, (B) diffusion-weighted imaging (DWI) performed 19 min after CTP, (C) CTA shows occlusion of MCA superior division segment, (D) DWI with acute infarct mapped in red, (E) CT head at $24 \mathrm{~h}$ from LKW, and (F) follow-up FLAIR image at 34 days post-stroke depicting final infarct. Note the CTP CBF hypoperfused region identified as $30 \%$ of mean contralateral hemisphere is much larger than that of the DWI scan, and corresponded better with tissue infarction on follow-up. Courtesy of William A. Copen, MD, Department of Radiology, Massachusetts General Hospital. Data analysis for figure was created under approval of local ethics committee.

reperfusion demonstrating small or no CBF volumes (due to normal or increased CBF values in previously hypoperfused tissue) that would grossly underestimate final infarct volume. However, these conditions are infrequent, and many trials and centers have adopted a CT-based approach to identify subjects with tissue at risk, using very low values in CTP-derived CBF values to define "core," with CTP-derived tracer arrival time metrics used to represent tissue at risk (5) at centers which do not perform acute stroke MRI. Although the accuracy of using a perfusion metric to define infarction "core" is still debated (60-62), this approach has successfully identified a group of patients who respond to reperfusion therapy beyond 3 - and 4.5-h time windows (see below). Some have suggested using thresholded relative cerebral blood volume (rCBV) maps to identify core (63) or absolute CBV values $<2 \mathrm{~cm}^{3} / 100 \mathrm{~g}(64,65)$, but many studies have shown that $\mathrm{CBV}$ is not a robust surrogate for infarct core (66-71). However, investigators have shown that very low $\mathrm{CBV}$ might be an indicator 
of risk for future hemorrhagic transformation (72-75) or poor outcome after $\operatorname{EVT}(76,77)$.

\section{Clinical Trials of Infarct Core-Perfusion Mismatch Involving Non-SUSO Patients}

There have been several trials applying the principles of infarct core-perfusion mismatch in the administration of IV thrombolytics to late-window AIS patients with varying degrees of success (Table 1). The Desmoteplase in Acute Ischemic Stroke Trials (DIAS and DIAS-2) used an alternative thrombolytic, desmoteplase (more specific for fibrin than alteplase) and coreperfusion mismatch $(>20 \%)$ for the treatment of late-window AIS patients 3-9 h from LKW $(78,79)$. DIAS was a dose escalation study of desmoteplase. Phase 1 of DIAS was halted because of high rates of sICH with desmoteplase doses of 25-50 mg (26.7\%) (78). Phase 2 of DIAS, however, showed that with desmoteplase doses of $62.5-125 \mu \mathrm{g} / \mathrm{kg}$ the rates of sICH were $2.2 \%$ and reperfusion rates were 71.4 vs. $19.2 \%$ with placebo. Of note, reperfusion in this trial was defined as a $\geq 30 \%$ reduction in mean transit time or $\geq 2$ points improvement on the Thrombolysis in Myocardial

TABLE 1 | Randomized clinical trials of delayed intravenous thrombolysis or EVT in acute ischemic stroke beyond $3 \mathrm{~h}$.

\begin{tabular}{|c|c|c|c|c|c|c|c|}
\hline Study & Study drug & Imaging selection & $\begin{array}{r}\text { No. of } \\
\text { treated }\end{array}$ & $\begin{array}{l}\text { Time } \\
\text { window }\end{array}$ & $\begin{array}{l}\text { sICH } \\
\text { definition }\end{array}$ & $\begin{array}{l}\text { Rate of } \\
\text { sICH (\%) }\end{array}$ & Primary outcome: intervention vs. placebo \\
\hline EPITHET (84) & Alteplase & $\begin{array}{l}\mathrm{MRI}(\mathrm{PWI} / \mathrm{DWI} \\
\text { mismatch) }\end{array}$ & 52 & $3-6 h$ & SITS-MOST & 7.7 & $\begin{array}{l}\text { Infarct growth between baseline and } 90 \text { days. Median } \\
\text { infarct growth ratio } 0.66(95 \% \mathrm{Cl} 0.36-0.92), P=0.054 \text {. }\end{array}$ \\
\hline DEDAS (80) & Desmoteplase & $\begin{array}{l}\mathrm{MRI}(\mathrm{PWI} / \mathrm{DWI} \\
\text { mismatch) }\end{array}$ & 29 & $3-9 h$ & ECASS ॥ & 0 & $\begin{array}{l}\text { Reperfusion at } 4-8 \text { h } 18.2 \% \text { (90 } \mu \mathrm{g} / \mathrm{kg}), 53.3 \% \\
(125 \mu \mathrm{g} / \mathrm{kg}) \text { vs. } 37.5 \% \text { (placebo). Good clinical } \\
\left.\text { outcome }^{\mathrm{a}} 28.6 \% \text { (90 } \mu \mathrm{g} / \mathrm{kg}\right), 60 \%(125 \mu \mathrm{g} / \mathrm{kg}) \\
\text { vs. } 25 \% \text { (placebo) }\end{array}$ \\
\hline DIAS part 2 (78) & Desmoteplase & $\begin{array}{l}\mathrm{MRI}(\mathrm{PWI} / \mathrm{DWI} \\
\text { mismatch) }\end{array}$ & 57 & $3-9 h$ & ECASS ॥ & 2.2 & 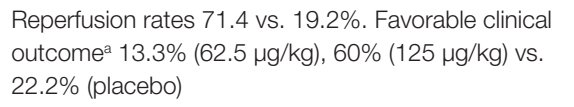 \\
\hline DIAS ॥ (79) & Desmoteplase & $\begin{array}{l}\mathrm{MRI}(\mathrm{PWI} / \mathrm{DWI} \\
\text { mismatch) or CTP }\end{array}$ & 125 & $3-9 h$ & ECASS ॥ & $3.5-4.5$ & $\begin{array}{l}\left.\text { Favorable clinical outcome }{ }^{a} 47 \% \text { (90 } \mu \mathrm{g} / \mathrm{kg}\right), 36 \% \\
(125 \mu \mathrm{g} / \mathrm{kg}), 46 \% \text { (placebo) }\end{array}$ \\
\hline DIAS 3 (82) & $\begin{array}{l}\text { Desmoteplase } \\
90 \mu \mathrm{g} / \mathrm{kg}\end{array}$ & $\begin{array}{l}\text { CTA/MRA high-grade } \\
\text { stenosis or occlusion } \\
\text { (<1/3 ACA/PCA } \\
\text { or }<1 / 2 \text { MCA) }\end{array}$ & 247 & $3-9 h$ & ECASS ॥ & 3 & $\begin{array}{l}\text { 90-day mRS 0-2: } 51 \% \text { vs. } 50 \%(a O R 1.2,95 \% \mathrm{Cl} \\
0.79-1.81 ; P=0.4)\end{array}$ \\
\hline DIAS 4 (83) & Desmoteplase & $\begin{array}{l}\text { CTA/MRA high-grade } \\
\text { stenosis or occlusion } \\
\text { (<1/3 ACA/PCA } \\
\text { or }<1 / 2 \mathrm{MCA})\end{array}$ & 124 & $3-9 h$ & ECASS ॥ & 4.8 & $\begin{array}{l}\text { 90-day mRS 0-2: } 41.9 \% \text { vs. } 35.9 \%(\mathrm{OR} 1.45,95 \% \mathrm{Cl} \\
0.79-2.64 ; P=0.23)\end{array}$ \\
\hline ECASS III (1) & Alteplase & $\mathrm{CT}(<1 / 3 \mathrm{MCA})$ & 418 & $3-4.5$ h & $\begin{array}{l}\geq 4 \mathrm{pt} \uparrow \mathrm{NIHSS} \\
\text { at } 72 \mathrm{~h} \text { due } \\
\text { to } \mathrm{ICH}\end{array}$ & 2.4 & $\begin{array}{l}\text { 90-day mRS 0-1: } 52.4 \% \text { vs. } 45.2 \%(\mathrm{OR} 1.34,95 \% \mathrm{Cl} \\
1.02-1.76 ; P=0.04) .\end{array}$ \\
\hline EXTEND $^{c}(121)$ & Alteplase & $\begin{array}{l}\text { MRI (PWI/DWI } \\
\text { mismatch) or CTP }\end{array}$ & 400 & $\begin{array}{l}3 \text { or } \\
4.5-9 h\end{array}$ & SITS-MOST & NA & 90-day mRS 0-1. \\
\hline MR RESCUE (89) & EVT & $\begin{array}{l}\text { MRI or CTP (voxel- } \\
\text { based algorithm) }\end{array}$ & 64 & $<8 \mathrm{~h}$ & SITS-MOST & 4 & Median 90-day mRS: 3.9 vs. 3.9. \\
\hline EXTEND-IA (5) & EVT & CTP mismatch & 35 & $4.5-6 \mathrm{~h}$ & SITS-MOST & 0 & 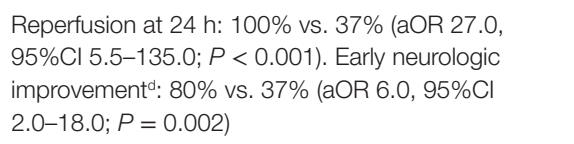 \\
\hline SWIFT-PRIME (4) & EVT & $\begin{array}{l}\mathrm{MRI}(\mathrm{PWI} / \mathrm{DWI} \\
\text { mismatch) }\end{array}$ & $98^{b}$ & $<6 \mathrm{~h}$ & $\begin{array}{l}\geq 4 \mathrm{pt} \uparrow \mathrm{NIHSS} \\
\text { at } 24 \mathrm{~h} \text { due } \\
\text { to } \mathrm{ICH}\end{array}$ & 0 & $\begin{array}{l}\text { 90-day mRS 0-2: } 60 \% \text { vs. 35\% (RR } 1.70,95 \% \mathrm{Cl} \\
1.23-2.33 ; P<0.001)\end{array}$ \\
\hline ESCAPE (48) & EVT & $\begin{array}{l}\text { Multiphase CTA and } \\
\text { collateral status }\end{array}$ & 120 & $<12 \mathrm{~h}$ & $\begin{array}{l}\geq 2 \text { pt } \uparrow \mathrm{NIHSS} \\
\text { due to any } \\
\mathrm{ICH}\end{array}$ & 3.6 & $\begin{array}{l}\text { 90-day mRS 0-2: } 53 \% \text { vs. } 29.3 \% \text { (cOR } 2.6,95 \% \mathrm{Cl} \\
1.7-3.8 ; P<0.001)\end{array}$ \\
\hline
\end{tabular}

${ }^{a}$ Combined analysis defined at 90 days as $\geq 8$ point improvement or scoring 0 to 1 on NIHSS, score of 0 to 2 on mRS, and a Bl score of 75 to 100 .

${ }^{b}$ Eighty-three patients treated using PWI/DWI mismatch. Fifteen patients treated based small-core defined as ASPECTS $\geq 6$ on CT or MRI.

-Trial completed or terminated but not yet published. Trial in progress.

${ }^{d}$ Early neurologic improvement defined as reduction of eight points or more on NIHSS or score of 0 or 1 at $72 \mathrm{~h}$.

ACA, anterior cerebral artery; CTA, CT angiogram; CTP, CT perfusion; DWI, diffusion weighted imaging; EVT, endovascular thrombectomy; MCA, middle cerebral artery; mRS, modified Rankin scale; NIHSS, National Institutes of Health Stroke Scale; PCA, posterior cerebral artery; PWI, perfusion weighted imaging.

sICH criteria: ECASS II: $\geq 4$ pt $\uparrow$ NIHSS and any ICH; NINDS: any neurologic worsening due to any ICH; PROACT II: $\geq 4 \mathrm{pt} \uparrow$ NIHSS at $36 \mathrm{~h}$ and any ICH; SITS-MOST: $\geq 4 \mathrm{pt} \uparrow$ NIHSS at $24 \mathrm{~h}$ and $\mathrm{PH} 2 \mathrm{HT}$. 
infarction grading scale (78). Although the trial was not powered to detect efficacy, at 90 days there was a dose-dependent rate of favorable outcome (defined as Barthel index $>75$, modified Rankin scale $(\mathrm{mRS}) \leq 2$, and NIHSS $0-1$ or improvement of 8 points) of $60 \%$ with $125 \mu \mathrm{g} / \mathrm{kg}$ vs. $18.2 \%$ placebo (78). The Dose Escalation of Desmoteplase for Acute ischemic Stroke (DEDAS) trial was a placebo-controlled, dose-escalation study of 90 and $125-\mu \mathrm{g} / \mathrm{kg}$ desmoteplase in 37 patients 3-9 h from LKW (80). No sICH occurred in any group and there appeared to be a dosedependent effect of desmoteplase on reperfusion rates $(53.3 \%$ $125-\mu \mathrm{g} / \mathrm{kg}$ desmoteplase vs. $18.2 \% 90-\mu \mathrm{g} / \mathrm{kg}$ desmoteplase vs. $37.5 \%$ placebo) (80). In DIAS-2, 186 patients were randomized to either 90 or $125-\mu \mathrm{g} / \mathrm{kg}$ desmoteplase or placebo $3-9 \mathrm{~h}$ from LKW utilizing the same infarct core-perfusion mismatch criteria. Notably, in addition to MRI, CTP was also used in DIAS-2 for assessing infarct core-perfusion mismatch (64 patients); however, mismatch was determined based on a visual, qualitative assessment. DIAS-2 had a favorable safety profile but there was no difference in the rates of favorable outcome at 90 days, median change in infarct volume, or rates of sICH (79).

Further analysis of DIAS, DIAS 2, and DEDAS was pursued given the disparate results of Phase- 2 trials (DIAS and DEDAS), suggesting efficacy and the negative efficacy results of Phase- 3 trial (DIAS 2). In comparing the patient populations of the three trials, it was noted that there was a substantial difference between DIAS 2 and DIAS/DEDAS in the number of patients with intracranial vascular occlusion or high-grade stenosis (DIAS $230 \%$ vs. DIAS/ DEDAS 57\%; $P \leq 0.0001$ ) (81). Moreover, in the pooled analysis of DIAS, DIAS 2, and DEDAS, desmoteplase treatment showed a favorable effect at 90 days in patients with either an intracranial vascular occlusion or high-grade stenosis (OR 4.14; 95\% CI 1.40-12.23; $P=0.01$ ) (81). Of note, favorable clinical response was defined as the composite of $\geq 8$ point improvement in NIHSS (or $0-1$ ), $\mathrm{mRS}<3$, and a Barthel Index Score $\geq 75$ at 90 days. The subsequent randomized control trials DIAS-3 (82) and DIAS-4 (83) notably did not require infarct core-perfusion mismatch for enrollment, but only occlusion or stenosis of proximal segments of the middle, posterior, or anterior cerebral arteries and acute infarct lesion (on DWI or non-contrast CT) involving less than $1 / 3$ MCA territory or $1 / 2$ the anterior cerebral artery (ACA) or PCA territory. Both studies showed no safety concerns, but also no benefit 90 -day functional outcomes $(\mathrm{mRS}<3$ ). Taken together, the results of the DIAS and DEDAS trials are mixed with regard to utilizing neuroimaging to select late-window stroke patients for treatment with thrombolytic therapy. On one hand, desmoteplase 3-9 h from LKW did not improve functional outcomes. However, a positive aspect of these studies was their demonstration that infarct core-perfusion mismatch can be effectively used in the emergent setting to efficiently triage acute stroke patients for potential treatment with thrombolytic therapy.

Around the same time that the DIAS 1-2 and DEDAS trials were underway to investigate desmoteplase with neuroimagingbased patient selection, several studies were simultaneously studying selection approaches for IV tPA using perfusion-diffusion mismatch. The Echoplanar Imaging Thrombolytic Evaluation Trial (EPITHET) was a Phase 2, observational trial of IV tPA in AIS patients 3-6 h from symptom onset (84). Out of
101 patients, $86 \%$ had perfusion-diffusion mismatch, using the same definition as DEFUSE. Of those patients that received IV tPA, there was decreased infarct growth (growth > 0\%: 54\% IV tPA vs. $77 \%$ placebo, $P=0.032$ ) and increased reperfusion $>90 \%$ (56\% IV tPA vs. $26 \%$ placebo, $P=0.01$ ). Overall, however, there was no difference in 90-day $\mathrm{mRS}$ between the IV tPA and placebo groups (mRS < 3: $45 \%$ IV tPA vs. $40 \%$ placebo, $P=0.66$ ). Post hoc analysis suggested that the previous failure of EPITHET was potentially due to too low a threshold for defining the PWI lesion $\left(T_{\max }>2 \mathrm{~s}\right)(85)$ and subsequent studies by these investigators have used a stricter threshold of $T_{\max }>6 \mathrm{~s}$ to define salvageable tissue.

An RCT used an alternative tissue plasminogen activator, tenecteplase, in AIS patients with infarct core-perfusion mismatch. This Phase-2B trial of tenecteplase for AIS, two doses of tenecteplase $(0.1$ or $0.25 \mathrm{mg} / \mathrm{kg})$ administered within $6 \mathrm{~h}$ of stroke onset, was compared with IV tPA (86). Eligibility criteria included a CTP mismatch of greater than $20 \%$ and verified occlusion of an anterior, middle, or PCA. Twenty-five patients were randomized to each group. For the co-primary endpoints, there appeared to be a dose-dependent effect of tenecteplase on the proportion of the perfusion lesion reperfused (as assessed by PWI) and improvement in NIHSS at $24 \mathrm{~h}$. In the pooled analysis, the tenecteplase group had higher rates of reperfusion at $24 \mathrm{~h}$ (79.3 vs. $55.4 \% ; P=0.004$ ), improvement in 24 -h NIHSS score (8.0 vs. $3.0 ; P<0.001$ ), reduced infarct growth at 90 days (2 vs. $\left.12 \mathrm{~cm}^{3} ; P=0.01\right)$, and increased rates of good functional outcome at 90 days ( $\mathrm{mRS}<2: 36$ vs. $11 \% ; P=0.02)(86)$. These promising findings prompted Phase 3, randomized tenecteplase trial (NORTEST) of 1,100 adults with AIS in 13 centers in Norway (87). No difference between the $0.4-\mathrm{mg} / \mathrm{kg}$ tenecteplase and IV tPA groups was observed for the primary outcome of 90-day mRS of 0-1 (64 vs. $63 \%$; $P=0.52$ ). Importantly, in contrast to the prior Phase- $2 \mathrm{~B}$ trial, there were no imaging inclusion criteria of documented occlusion of an intracranial artery or any perfusion mismatch. As a result, $17 \%$ of enrolled patients were later confirmed as stroke mimics. Lastly, the randomized control trial of $0.25-\mathrm{mg} / \mathrm{kg}$ tenecteplase in patients with WUS, Tenecteplase in Wake-up Ischemic Stroke Trial (TWIST), is currently ongoing (88).

Similar studies have also been conducted using infarct coreperfusion mismatch criteria for patient selection for EVT. The Mechanical Retrieval and Recanalization of Stroke Clots Using Embolectomy (MR RESCUE) trial was the first trial initiated using the concept of core-perfusion mismatch for AIS patient triage (89). MR RESCUE was a Phase $2 \mathrm{~b}$, multicenter, randomized, open-label study of anterior circulation LVO patients, within $8 \mathrm{~h}$ of LKW, to EVT vs. usual medical care. Patients were stratified according to a favorable vs. non-favorable penumbral pattern that was defined as a predicted infarct core of $<90 \mathrm{~cm}^{3}$ and proportion of predicted infarct tissue within region of interest as $<70 \%$. Unlike the definition of core-perfusion mismatch utilized in other trials, MR RESCUE employed a complex voxel-by-voxel algorithm requiring 4-7 variables on CTP or PWI (90). No difference was observed in mean 90 -day mRS (3.9 vs. 3.9, $P=0.99$ ); however, there were several important limitations important in considering the overall results of this trial. First, the trial used first-generation thrombectomy devices. Second, the trial had 
an exceedingly difficult time with enrollment, taking 7 years to enroll 118 patients across 22 high-volume stroke centers, likely due to a bias to randomize patients at enrolling sites. Next, in contrast to the subsequent positive EVT trials, subjects in MR RESCUE in the embolectomy, favorable penumbral arm had large estimated core volumes (median $36.2 \mathrm{~cm}^{3}$ ) and low rates (24\%) of successful revascularization defined as a thrombolysis In Cerebral Infarction scale 2b/3. Lastly, the automated imaging program for penumbral stratification failed in $42 \%$ of cases.

EXTEND-IA used automated imaging analysis of CTP to select patients with occlusion of the intracranial ICA or first or second segment of the MCA and with salvageable tissue profile for EVT within $6 \mathrm{~h}$ from LKW. The mismatch profile was defined as follows: perfusion lesion $T_{\max }>6 \mathrm{~s}$, "infarct core" low CTP $\mathrm{rCBF}<30 \%$ normal tissue, low $\mathrm{rCBF}$ volume $<70 \mathrm{~cm}^{3}$, mismatch ratio $>1.2$, and absolute mismatch volume $>10 \mathrm{~cm}^{3}$. EVT initiated within $6 \mathrm{~h}$ of stroke onset and combined with mismatch for patient selection (see, e.g., Figure 5) significantly increased the likelihood of a favorable outcome (90-day mRS: generalized odds ratio, 2.0 ; $95 \% \mathrm{CI} 1.2-3.8$; 90 -day $\mathrm{mRS}<3$ : 71 vs. $40 \%$; $P=0.01$ ) (5). EXTEND-IA demonstrated that early EVT, in combination with perfusion mismatch, was feasible for acute decision-making of LVO patients with SKSO. Moreover, in this trial EVT within 6 $\mathrm{h}$ of stroke onset was efficacious for reducing long-term disability.

These trials of late-window intravenous thrombolytic therapy and endovascular treatment have confirmed that advanced neuroimaging techniques can be employed in the emergent setting to triage acute stroke patients for acute therapies. As we will discuss

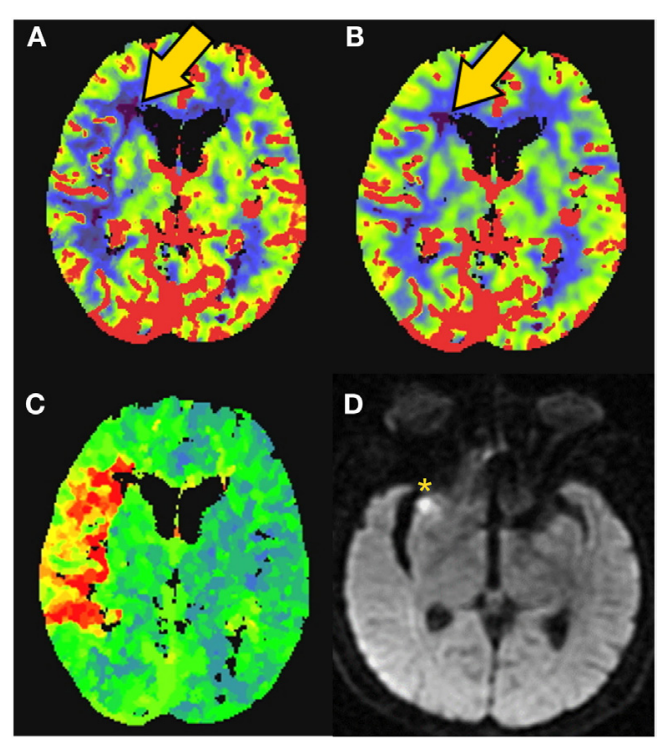

FIGURE 5 | CT perfusion to identify salvageable tissue. 81-year-old female with right middle cerebral artery (MCA) syndrome and occlusion of the MCA on CT-angiogram. CT-perfusion maps: (A) cerebral blood flow (CBF), (B) cerebral blood volume (CBV), and (C) time to peak (TTP). Elevated time-to-peak contrast enhancement (TTP) colors orange to red represent $>6$ s delay (C). Severely low blood flow and volume territories are violet color (gold arrow). The patient was rapidly revascularized and the final infarction is demonstrated on MRI diffusion weighted imaging [(D)—yellow asterisk]. Data analysis for figure was created under approval of local ethics committee. below, these studies have prompted the application of infarct core-perfusion mismatch to the selection process of late-window or SUSO patients for revascularization therapies.

\section{Clinical-Core Mismatch}

An alternative approach to treating patients with sufficient salvageable "penumbra" tissue to make the likely benefit of reperfusion therapy outweigh its risk is to treat patients with large clinical--"core" mismatches. In one study (91), the authors demonstrated that in 166 patients imaged within $12 \mathrm{~h}$ of onset with small "core" (DWI lesion $\leq 25 \mathrm{~mL}$ ), but large clinical deficits (NIHSS $\geq 8$ ) were more likely to experience early neurological deterioration (increase of NIHSS $\geq 4$ points). Similar findings were found in 87 patients imaged within $24 \mathrm{~h}$ of LKW using DWIASPECTS $\geq 8$ score to define core (92). Another study showed that such clinical-diffusion mismatches are also associated with perfusion-diffusion mismatch, with $93 \%$ specificity and $53 \%$ sensitivity in 54 patients imaged within $24 \mathrm{~h}$ of LKW (93). However, a separate study showed clinical-diffusion mismatch predicted perfusion-diffusion mismatch with only $65 \%$ sensitivity and $42 \%$ specificity in 68 patients (94). While another cohort study of 99 patients showed that clinical-diffusion mismatch was only $46 \%$ sensitive but $86 \%$ specific for perfusion-diffusion mismatch, benefits of IV tPA and reperfusion were similar in both patient groups with or without clinical-diffusion mismatch (95). On the other hand, in 43 EVT-eligible patients (M1 segment of the MCA-occlusion) with DWI lesions $<25 \mathrm{~mL}$, clinical-diffusion mismatch was found to be a better predictor of infarct growth than perfusion-diffusion mismatch (96). There have also been studies of non-contrast CT-based approaches for clinical-core mismatches. One investigation found no combination of CT ASPECTS and NIHSS predicted perfusion-diffusion mismatch (97) and another study found no relationship between "clinical-CT mismatch" and likelihood of responding to IV tPA (98). Researchers have also shown that EVT decisions were changed rarely (5.6\%) when including CTP in addition to NIHSS, noncontrast CT and CTA (99).

SWIFT PRIME, a prospective, randomized open-label clinical trial, which showed benefit for EVT for anterior circulation LVO stroke patients within $6 \mathrm{~h}$ of LKW also employed a modified clinical--"core" mismatch for part of the study (4). Patients were originally excluded based on MRI- or CT-assessed infarct core $>50 \mathrm{~cm}^{3}$, ischemic penumbra $<15 \mathrm{~cm}^{3}$, and mismatch ratio <1.8. After enrollment of the first 71 patients in SWIFT PRIME using infarct core-perfusion mismatch as part of its inclusion criteria, the approach was modified to accommodate study sites without perfusion imaging capabilities based only on the extent of ischemic changes on CT (ASPECTS $\geq 6$ ) (4). Thirtyseven patients were enrolled with this modified inclusion criteria based on core size. Patients treated with Stent Retriever plus IV tPA were significantly more likely to be functionally independent at 90 days ( $\mathrm{mRS}<3: 60$ vs. $35 \%$; risk ratio $1.70,95 \% \mathrm{CI} 1.23-2.33$; $P<0.001)$.

The results of these studies provide evidence that clinical- "core" mismatch can function as an indicator of potentially salvageable tissue in the decision-making processes of acute stroke. A major advantage of this approach for patient triage is 
the independence from relying on perfusion imaging, which is not universally available at all hospitals that treat AIS patients. The best evidence for benefit in the late-window (beyond $6 \mathrm{~h}$ for EVT) currently relies on core volume estimates either by DWI, or by CT-rCBF, which implies that stroke centers of all levels will eventually need to become facile with some form of advanced imaging in late-window patients. In later sections, we will discuss the recent clinical trials that used this approach to expand the window of eligibility for thrombolysis in SUSO patients.

\section{Collateral Grade}

A third approach for selecting patients for late thrombolysis relies on the status of the pial collaterals. This is also a pragmatic approach for EVT candidates since all patients are screened with vessel imaging to identify LVO that obviates additional imaging. Studies have shown that patients with a malignant CTA profile, defined as the absence of collaterals in $>50 \%$ of an MCA M2 branch, also have large DWI lesions (100). A retrospective analysis of the IMS III trial of 95 patients with both diagnostic-quality CTA and CTP showed that patients presenting with good collaterals tend to have smaller cores and greater perfusion mismatch (101). In addition, in 276 patients with CTA, robust collaterals were associated with good clinical outcomes (102). However, another study of 60 patients imaged within $12 \mathrm{~h}$ of LKW showed that patients with target perfusion-diffusion mismatch did well irrespective of collateral score (103). In ESCAPE, which was the Canadian multicenter randomized Phase-3 trial of EVT for LVO in 316 patients up to $12 \mathrm{~h}$ from LKW, a notable, distinct inclusion criterion was evidence of moderate-to-good collateral circulation of the MCA territory on multiphase CTA (48). Importantly, $6.3 \%$ of participants enrolled had evidence of poor collateral circulation on analysis by the core laboratory. Although patients could be enrolled up to $12 \mathrm{~h}$ from LKW, the median time from LKW to reperfusion was approximately $4 \mathrm{~h}$, with only 49 subjects randomized after $6 \mathrm{~h}$, and thus the ESCAPE study cannot be considered a comprehensive study of late revascularization intervention.

These observations suggest that collateral status can function as another imaging surrogate of salvageable tissue. Specifically, patients with good pial collaterals are more likely capable of sustaining salvageable tissue for relatively longer periods of time and thereby could be candidates for extended window therapeutic interventions. Collateral status is likely an important variable in determining the rate of tissue death over time in hypoperfused brain. While there is a correlation between collateral status and CTP $(101,104)$, it is unclear whether collateral status is superior to CTP in the triage of SUSO patients.

\section{RETROSPECTIVE STUDIES OF OFF-LABEL REVASCULARIZATION TREATMENT OF SUSO PATIENTS}

Because of encouraging studies characterizing SUSO patients and suggesting a potential benefit of reperfusion therapy due to similarity in imaging presentation with early witnessed stroke patients; there have been several retrospective analyses of patients who were treated with off-label IV tPA or EVT (Table 2) based on imaging techniques described previously. We will discuss briefly the safety and efficacy findings in these retrospective studies that paved the way for the pivotal prospective trials of extended window intervention of AIS patients.

\section{Intravenous Thrombolysis}

A retrospective analysis of 32 SUSO patients treated with thrombolytic therapy at 3 Korean medical centers using MRI specific eligibility criteria (perfusion-diffusion mismatch $>20 \%$ MTT to DWI, no FLAIR changes, and DWI volume $<50 \%$ MCA territory) showed that an MRI-based algorithm for thrombolysis of SUSO patients was feasible. In comparing the SUSO to SKSO groups, baseline characteristics were similar, including age and admission NIHSS scale, and no difference was observed in rates of recanalization (immediate 81.3 vs. $63.1 \% ; P=0.06$; delayed 80.6 vs. $69.1 \% ; P=0.28$ ), 90 -day $\mathrm{mRS} \leq 2$ (50 vs. $49.3 \%, P=1.0$ ), or $\mathrm{sICH}$ (6.3 vs. $5.8 \% ; P=1.0)(105)$.

In another retrospective single-center study of thrombolytic therapy for WUS, administered on a compassionate basis, criteria for thrombolytic therapy in the WUS cohort included the following: (1) patients were neurologically normal before going to sleep,

TABLE 2 | Retrospective studies of off-label revascularization treatment of SUSO patients.

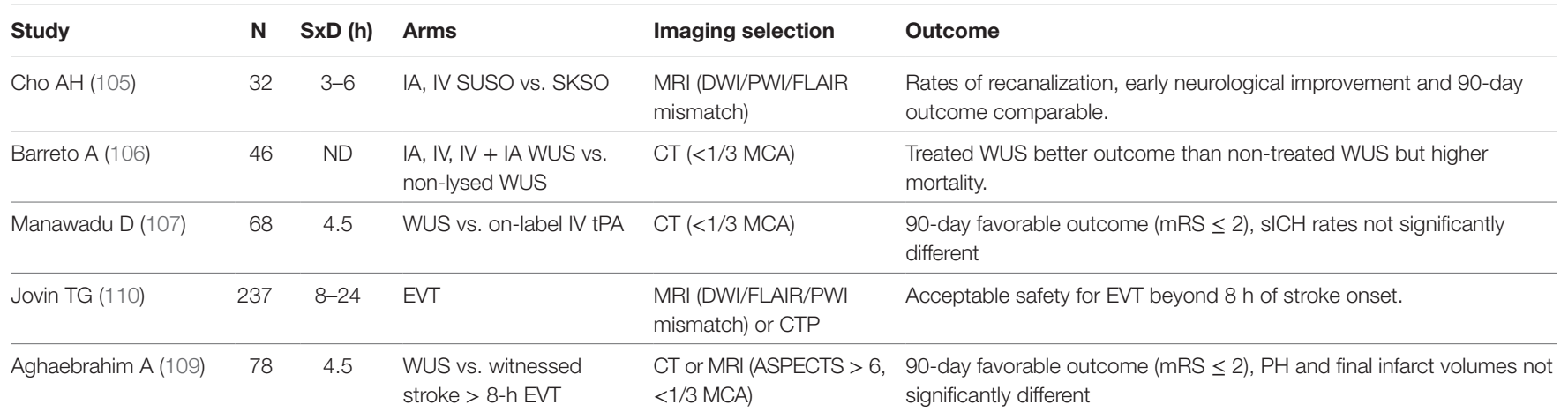

CT, computed tomography; DWI, diffusion-weighted imaging; EVT, endovascular thrombectomy; FLAIR, fluid attenuated inversion recovery; IA, intra-arterial; ICH, intracranial hemorrhage; IV, intravenous; MCA, middle cerebral artery; MRI, magnetic resonance imaging; mRS, modified Rankin scale; PH, parenchymal hematoma; PWI, perfusion weighted imaging; sICH, symptomatic intracranial hemorrhage; SKSO, stroke of known symptom onset; SUSO, stroke of unknown symptom onset; WUS, wake-up stroke. 
(2) patients awakened with a disabling deficit, and (3) CT head showed no hypodensity exceeding 1/3 the MCA (106). Forty-six WUS patients that received thrombolytic therapy were identified, of which $61 \%$ were treated with IV tPA and $30 \%$ with only EVT and the remaining receiving combination treatment (106). In the thrombolysed WUS group, two patients experienced sICH (4.3\% thrombolysed WUS vs. 0\% non-treated WUS). Despite higher mortality (15 vs. $0 \%$ ) compared with non-treated WUS patients, thrombolysed WUS patients were more likely to experience a favorable outcome (90-day mRS 0-2: 28 vs. $13 \%, P=0.006)$ (106). Compared with 174 standard-of-care 0 to 3 -h IV tPA-treated patients, treated WUS patients had higher rates of sICH (4.3 vs. $2.9 \% ; P=0.64)$ and a lower, but statistically insignificant, likelihood of favorable outcome ( 28 vs. $48 \%, P=0.64$ ).

A retrospective analysis of 68 WUS patients presenting within 4.5-12 h from LKW and treated with thrombolytic therapy from another center showed no difference in the number of patients achieving a 90 -day mRS of $0-2(38$ vs. $37 \%, P=0.89)$ or rate of symptomatic ICH (sICH: 3.4 vs. $2.9 \%, P=1.0$ ) compared with 326 patients receiving IV tPA within $4.5 \mathrm{~h}$ of symptom onset (107). Notable inclusion criteria for the WUS group included: NIHSS $\geq 5$ and no or early ischemic changes $<1 / 3$ MCA territory as assessed by ASPECTS (107).

\section{Endovascular Treatment}

With regard to EVT, a retrospective, single-center study of EVT without any advanced neuroimaging in WUS patients has also been reported. In $213 \mathrm{LVO}$ anterior circulation ischemic stroke patients that underwent EVT after being deemed ineligible for IV tPA, including 21 WUS patients and 33 patients treated beyond 8 $\mathrm{h}$ from LKW, an increased odds of $\operatorname{sICH}(14.3 \%$; odds ratio $=4.9$, 95\%CI 1.03-23.6; $P=0.047)$ in WUS patients compared with the group treated within $8 \mathrm{~h}$ of symptom onset (6.7\%; odds ratio 3.8 , 95\%CI 1.07-13.7; $P=0.04$ ) (108). Despite this observation, the authors reported no difference in the 90 -day mRS between the WUS and group treated within $8 \mathrm{~h}$ of stroke onset (108). Another retrospective, single-center review of EVT comparing outcomes between 78 WUS patients and 128 late-window (beyond $8 \mathrm{~h}$ from LKW) SKSO patients who presented with small core and large perfusion defect found similar results (109). No significant difference was observed in baseline NIHSS, rates of successful recanalization, 90 -day $\mathrm{mRS} \leq 2$ (43 vs. $50 \%, P=0.3$ ), parenchymal hematoma ( 9 vs. $5.5 \% ; P=0.3$ ), or final infarct volume $(75.2$ vs. $\left.61.4 \mathrm{~cm}^{3} ; P=0.6\right)$.

A multicenter, retrospective analysis of patients with LVO (EVT initiated beyond $8 \mathrm{~h}$ from LKW) and perfusion imaging used for selection criteria suggested feasibility and potential efficacy of late-window EVT (110). In 237 patients meeting those inclusion criteria the mean treatment time was $15 \mathrm{~h}$ from LKW. Forty-five percent of the patients achieved a good functional outcome at 90 -days or time of hospital discharge $(\mathrm{mRS}<3$ ). Parenchymal hematoma occurred in $8.9 \%$ of the patients and the 90-day mortality rate was $21.5 \%$.

In addition to perfusion imaging, the status of the pial collateral circulation has also been evaluated as a potential metric for extending the window for EVT eligibility. A retrospective, singlecenter study of 61 anterior circulation LVO patients showed that in contrast to patients with poor collateral status, patients with good pial collaterals had no temporal cutoff point for total time of ischemia and predicting clinical improvement (111). In comparing good vs. poor collateral status, clinical improvement (4-point decline in NIHSS from baseline to discharge) beyond 300 min was significantly higher in the group with good pial collaterals ( 90.1 vs. $23.1 \% ; P=0.010)$. In agreement with these findings, another retrospective analysis of 237 patients with anterior circulation LVOs undergoing EVT also demonstrated that in patients with good collateral grades the probability of favorable outcome is not significantly influenced by onset-to-reperfusion time (112).

The interpretation of these retrospective studies is limited by the retrospective nature and inconsistency in neuroimaging selection criteria. Nonetheless, these findings demonstrate that neuroimaging-based triage for EVT is feasible and safe beyond 8 $\mathrm{h}$ from LKW and prompted the development of several prospective studies to further assess for efficacy.

\section{PROSPECTIVE CLINICAL TRIALS OF REVASCULARIZATION THERAPIES FOR SUSO PATIENTS}

\section{Intravenous Thrombolysis}

Based on the promising findings of retrospective studies of revascularization interventions for SUSO patients, several prospective studies have been launched (Table 3). In 2003, one of the earliest studies involved abciximab, which had a prespecified cohort of WUS patients, although the primary cohort involved patients that could be treated within $5 \mathrm{~h}$ of stroke onset. Phase-3 RCT of abciximab (AbESTT-II), which is a platelet glycoprotein IIb/ IIIa inhibitor, was terminated early in 2005 due to a significantly increased rate of symptomatic and fatal ICH (5.5\% of abciximabtreated vs. $0.5 \%$ placebo, $P=0.002$ ) (113). Of the WUS cohort (43 patients, 22 treated with abciximab, 21 treated with placebo), there was no improvement in 90-day $\mathrm{mRS}$ and an increased rate of symptomatic and fatal $\mathrm{ICH}$ at 5 days (13.6 vs. $5 \%$ placebo, $P=0.347)$ and 3 months ( 18.2 vs. $5 \%, P=0.193)$ Secondary analysis showed that the WUS cohort who received abciximab tended to have greater rates of new strokes on baseline CT and bleeding but otherwise were comparable to other patients in the study (114).

In 2013, another WUS investigation, Wake-up Stroke, completed involving a single-arm prospective open-label, multicenter safety trial of 40 WUS patients treated with IV tPA within $3 \mathrm{~h}$ of symptom discovery (115). The median NIHSS of this cohort was 6.5 and IV tPA was administered at a mean time of $10.3 \pm 2.6$ $\mathrm{h}$ from LKW. No sICH occurred in this population and $52.6 \%$ had an excellent functional outcome at 90 days (mRS 0-1) (115). While this trial is limited by its relatively small sample size, lack of control group, and open-label design, the strength of this trial is its pragmatic triage requirement of only a non-contrast head CT. A similarly designed prospective open-label, multicenter safety trial of IV tPA treatment within 4.5 h of symptom discovery of 20 WUS patients, Safety of intravenous thrombolytics in stroke on awakening (SAIL-ON), also reported no sICH (116). Both these 
TABLE 3 | Prospective trials of thrombolysis in WUS and non-WUS SUSO patients.

\begin{tabular}{|c|c|c|c|c|c|c|c|c|c|}
\hline Study & Phase & $N$ & SxD (h) & Design & Study drug & Imaging selection & $\begin{array}{l}\text { sICH } \\
\text { definition }\end{array}$ & sICH (\%) & Primary outcome \\
\hline AbESTT- $\|^{a}$ & 3 & 808 & 3 & Two arms & $\begin{array}{l}\text { Abciximab, } \\
\text { placebo }\end{array}$ & CT $(<50 \%$ MCA $)$ & NINDS & 5.5 & $\begin{array}{l}\text { 90-day mRS adjusted } \\
\text { for stroke severity: } 32 \% \\
\text { vs. } 33 \% \text {. }\end{array}$ \\
\hline Wake-up Stroke ${ }^{e}$ & 2 & 40 & 3 & Open label & IV tPA & CT (<1/3 MCA) & ECASS III & 0 & $\begin{array}{l}\mathrm{sICH} ; 52.6 \% 90 \text {-day } \\
\mathrm{mRS}<2\end{array}$ \\
\hline Aoki (118) & NA & 10 & 3 & $\begin{array}{l}\text { Open label, } \\
\text { Single arm }\end{array}$ & IV tPA & $\begin{array}{l}\mathrm{MRI}(\mathrm{DWI} / \mathrm{FLAIR} \text { signal intensity } \\
\text { ratio) }\end{array}$ & ECASS III & 0 & $\begin{array}{l}90 \text {-day favorable } \\
\text { outcome (mRS } \leq 2) \\
\text { found in four patients. }\end{array}$ \\
\hline SAIL-ON & 2 & 20 & 4.5 & Open label & IV tPA & CT or MRI (<1/3 MCA) & $\begin{array}{l}\text { ECASS } \| \\
\text { NINDS }\end{array}$ & 0 & $\mathrm{sICH}$ \\
\hline RESTORE ${ }^{d}$ & 2 & 83 & 6 & $\begin{array}{l}\text { Open label, } \\
\text { Single arm }\end{array}$ & $\begin{array}{l}\text { IV tPA/IV + IA } \\
\text { UK or IA UK }\end{array}$ & MRI (DWI/PWI/FLAIR) & $\begin{array}{l}\text { ECASS } \| \text {, } \\
\text { NINDS }\end{array}$ & 3.6 & 90-day mRS 0-2: 44.6\%. \\
\hline MR WITNESS & 2 & 80 & 4.5 & Open label & IV tPA & $\begin{array}{l}\text { MRI (DWI/FLAIR signal intensity } \\
\text { ratio) }\end{array}$ & ECASS III & 1.25 & $\mathrm{sICH}$ \\
\hline WAKE-UPc,e & 3 & 800 & 4.5 & Two arms & IV, placebo & MRI (DWI/FLAIR mismatch) & $\begin{array}{l}\text { ECASS II, } \\
\text { SITS-MOST, } \\
\text { NINDS }\end{array}$ & NA & 90-day mRS 0-1 \\
\hline THAWS & 3 & 300 & 4.5 & Two arms & IV, placebo & MRI (DWI/FLAIR mismatch) & $\begin{array}{l}\text { ECASS II, } \\
\text { SITS-MOST, } \\
\text { NINDS }\end{array}$ & NA & $\begin{array}{l}\text { 90-day mRS 0-1 in } \\
\text { Japanese stroke patients. }\end{array}$ \\
\hline DAWN $^{\mathrm{b}}$ & $2 / 3$ & 206 & $6-24 \mathrm{~h}$ & Two arms & EVT & $\begin{array}{l}\text { CT or MRI (<1/3 MCA, ICA } \\
\text { M1 occlusion, clinical/NIHSS } \\
\text { mismatch) }\end{array}$ & ECASS III & 6 & $\begin{array}{l}\text { 90-day mRS 0-2: } 48.6 \% \\
\text { vs. } 13.1 \% .\end{array}$ \\
\hline DEFUSE $3^{\mathrm{b}}$ & 3 & 182 & $6-16 \mathrm{~h}$ & Two arms & EVT & $\begin{array}{l}\text { ICA/M1 occlusion, target } \\
\text { mismatch }\end{array}$ & ECASS ॥ & 7 & $\begin{array}{l}\text { 90-day mRS 0-2: } 45 \% \\
\text { vs. } 17 \% .\end{array}$ \\
\hline \multicolumn{10}{|c|}{$\begin{array}{l}\text { aTerminated (808 enrolled). } \\
\text { 'Halted for overwhelming efficacy. } \\
\text { 'Halted for funding stoppage. } \\
\text { 'Treatment group compared with registry of controls. } \\
\text { eTrial enrolled on wake-up stroke patients. } \\
\text { CT, computed tomography; DWI, diffusion-weighted imaging; EVT, endovascular thrombectomy; FLAIR, fluid attenuated inversion recovery; IA, intra-arterial; ICH, intracranial } \\
\text { hemorrhage; IV, intravenous; MCA, middle cerebral artery; MRI, magnetic resonance imaging; mRS, modified Rankin scale; PH, parenchymal hematoma; PWI, perfusion weighted }\end{array}$} \\
\hline
\end{tabular}

trials enrolled stroke mimics, which might have contributed to the high rates of good outcome.

In parallel with the CT trials, MRI-based trials were underway investigating imaging-selected revascularization of SUSO patients. Launched in 2006, RESTORE (Reperfusion therapy in unclear-onset stroke based on MRI evaluation) was a prospective, multicenter, single-arm trial of SUSO patients with thrombolytic therapy within $6 \mathrm{~h}$ of symptom discovery (117). Patients were included if presenting with perfusion-diffusion mismatch, but excluded if FLAIR hyperintensities were noted. Out of 430 SUSO patients, 83 patients were treated with thrombolytic therapy including 63 WUS patients (117). Of those treated SUSO patients, the median LKW to hospital presentation was $8.6 \mathrm{~h}$ (interquartile range $5.4-11.1 \mathrm{~h}$ ). In total, $89.2 \%$ of patients had an LVO and $68.7 \%$ of patients received only intra-arterial therapy, which included intra-arterial urokinase mechanical clot disruption, or angioplasty. At 3 months, $44.6 \%$ of patients had an mRS $<2$ and only $3.6 \%$ had sICH. Compared with the non-treated registrybased control group, the treated group had increased odds of good outcome (mRS 0-2: OR 2.25; 95\% CI 1.14-4.49) suggesting a potential benefit of revascularization therapy in this population.
However, the interpretation and generalizability of these results are limited due to the use of registry patients as the control group. The RESTORE trial can be considered more aptly an investigation of perfusion-diffusion mismatch enrollment criteria, with an additional restriction of FLAIR negativity.

There have been trials that investigated directly the concept of using DFM for patient selection. In 2009, there was a small prospective trial of IV tPA $(0.6 \mathrm{mg} / \mathrm{kg})$ of SUSO patients with ICA or MCA M1 or M2 occlusions based on DFM who could be treated within $3 \mathrm{~h}$ of symptom discovery [fluid attenuated inversion recovery imaging-based intravenous recombinant tissue plasminogen activator (rt-PA) therapy study] (118). Ten subjects were enrolled, of which four were WUS. Favorable outcome was defined as mRS 0-2. No sICH was observed in this group and seven of the patients had recanalization at 7 days after IV tPA administration. Favorable outcome was observed in $40 \%$ of subjects. Notably $30 \%$ of the subjects had prestroke mRS greater than 2. In 2011, the MR WITNESS trial (A Study of Intravenous Thrombolysis with Alteplase in MRI-Selected Patients), a Phase $2 \mathrm{a}$, open-label multicenter trial of IV tPA $(0.9 \mathrm{mg} / \mathrm{kg})$ in SUSO patients with DFM 4.5-24 h from LKW, launched (119). This 
trial enrolled 80 subjects with a primary safety outcome of sICH in only 1 subject, and a rate of excellent functional outcome at 90 days (mRS $0-1$ ) of $44 \%$ among the 69 subjects with a prestroke $\mathrm{mRS}$ of $0-1$. In summary, these findings suggest that the administration of IV tPA to SUSO patients within $3 \mathrm{~h}$ of symptom discovery is safe and feasible.

Two large, prospective clinical trials assessing DFM in the triage of AIS patients are in progress or recently completed that address efficacy issues. The Thrombolysis for Acute Wake-up and unclear-onset Strokes (THAWS) is a multicenter, prospective, open-label trial currently enrolling in Japan that is investigating a lower dose of IV tPA $(0.6 \mathrm{mg} / \mathrm{kg}$, which is the approved dose for Japanese stroke patients) in patients with stroke onset 4.5-12 h from LKW and DFM on MRI (120). The anticipated enrollment is 300 patients and the primary outcome measures are 90 -day $\mathrm{mRS}<2$ and sICH. WAKE-UP (Efficacy and Safety of MRI-Based Thrombolysis in Wake-Up Stroke: A Randomized, Double-blind, Placebo-controlled Trial) is a European multicenter, randomized placebo-controlled, Phase-3 trial using DFM as criterion for IV tPA treatment of AIS patients with $>4.5 \mathrm{~h}$ LKW (30). This study was stopped due to lack of funding and results are anticipated this year. Out of 1,362 patients enrolled, 503 were randomized (planned 800) and 859 participants were screen failures. In Tables 2 and 3, we summarize the major prospective and retrospective studies on thrombolytic therapy of SUSO including WUS.

In addition to DFM trials, there is also a large Phase- 3 trial Extending the time for Thrombolysis in Emergency Neurological Deficits (EXTEND) trial which uses infarct core-perfusion mismatch in patients 3 or 4.5-9 h from LKW or WUS within $9 \mathrm{~h}$ from midpoint of sleep duration to determine eligibility for treatment with IV tPA (121). The neuroimaging inclusion criteria of this trial are (1) a small "infarct core" defined as DWI or CT-rCBF lesion volume $<70 \mathrm{~cm}^{3}$ and (2) core-perfusion mismatch $>1.2$ and absolute mismatch $>10 \mathrm{~cm}^{3}$. The perfusion lesion is defined on PWI or CTP as $T_{\max }>6 \mathrm{~s}$. The primary outcome is rate of 90-day mRS 0-1 outcomes in the IV tPA group compared with the placebo group. The expected enrollment is 400 patients with an anticipated completion date of 2019.

While the current evidence for pretreatment advanced neuroimaging to guide decision-making for IV thrombolytic therapies in SUSO patients is intriguing, at present, there is no positive Phase- 3 trial to warrant the routine use in clinical practice. This statement is supported by the 2018 American Heart Association/ American Stroke Association Guidelines recommendation of no benefit to this approach (11). There is therefore a clinical opportunity to expand IV tPA to more patients outside the current approved treatment window of $4.5 \mathrm{~h}$ from LKW with such a trial.

\section{Endovascular Treatment}

The recently published DAWN trial represents the first randomized, multicenter, Phase-3 trial utilizing an automated neuroimaging approach to triage late-window LVO patients for EVT (8). Distinct from the previously discussed studies, DAWN employed the concept of clinical-ischemic core mismatch to identify LVO patients with occlusion of the intracranial ICA and/or first segment of the MCA that were hypothesized to benefit from EVT. The inclusion criteria were therefore a combination of NIHSS and age-dependent infarct volume assessed by DWI or rCBF volume. Specifically, LVO patients 6-24 h from LKW and age less than 80 years were eligible if infarct volume was $<31 \mathrm{~cm}^{3}$ and NIHSS $\geq 10$ or infarct volume was $31-51 \mathrm{~cm}^{3}$ and NIHSS $\geq 20$. For LVO patients greater than 80 years of age, inclusion criteria were NIHSS $\geq 10$ and infarct volume $<21 \mathrm{~cm}^{3}$ (8). A total of 206 patients were enrolled in the trial with 107 randomized to EVT. The median time from LKW to randomization was $12.2 \mathrm{~h}$ in the EVT group. The trial was stopped early for overwhelming efficacy according to a prespecified interval assessment. At 90 days, $49 \%$ of the EVT group vs. $13 \%$ of the standard medical therapy group achieved functional independence ( $\mathrm{mRS}<3$; 95\% credible interval 24-44; posterior probability of superiority, $>99.9 \%)$. There was no difference in the rate of sICH (6 vs. $3 \% ; P=0.5$ ) or 90 -day mortality (19 vs. $18 \% ; P=1.0)$ in the EVT group compared with standard medical therapy (8).

The DEFUSE-3 trial also showed substantial benefit of EVT from an infarct core-perfusion mismatch strategy of LVO patient selection 6-16 h after onset (7). DEFUSE 3 used the same neuroimaging definition of core-perfusion mismatch as DEFUSE 2 using MRI or CT-rCBF (infarct core $<70 \mathrm{~cm}^{3}$, mismatch ratio $\geq 1.8$, mismatch volume $\geq 15 \mathrm{~cm}^{3}$ ) in patients with anterior circulation LVO (defined as ICA or M1 segment MCA). Importantly, as a result of DAWN, the trial was halted prematurely for an interim analysis, which exceeded the efficacy endpoint. Of the 92 patients that were randomized to EVT, 53\% were WUS and 75\% received CTP to assess for core-perfusion mismatch. Both the EVT and standard medical therapy groups had small ischemic cores (9.4 $\mathrm{cm}^{3}$ EVT vs. $10.1-\mathrm{cm}^{3}$ medical therapy) and large hypoperfused areas (114.7- $\mathrm{cm}^{3}$ EVT vs. $116.1-\mathrm{cm}^{3}$ medical therapy). EVT plus standard medical therapy significantly reduced disability assessed by 90 -day mRS (unadjusted common odds ratio $2.77,95 \% \mathrm{CI}$ 1.63-4.70; mRS 0-2 45\% EVT vs. $17 \%$ standard medical therapy, $P<0.001)$. There was no difference in sICH between groups (7 vs. $4 \% ; P=0.75$ ).

There are several additional points of DEFUSE 3 that further inform on the approach of core-perfusion mismatch in the triage of late-window LVO patients. First, of the 296 patients originally consented, 107 patients did not fulfill imaging inclusion criteria (36.1\%). Secondly, 70 patients included in DEFUSE 3 would have been ineligible for DAWN, largely based on ischemic core size; however, the DAWN-ineligible group showed a similar benefit for late-window EVT (odds ratio 2.96, 95\%CI 1.26-6.97). This observation speaks to the potential for core-perfusion mismatch to expand eligibility for reperfusion therapies beyond clinicalcore mismatch. Third, WUS patients also showed a similar benefit of EVT (odds ratio 3.44, 95\% CI 1.60-7.38). Lastly, and somewhat surprisingly, at 24 -h post-revascularization therapy there was no significant difference in median infarct volume between groups $\left(35-\mathrm{cm}^{3}\right.$ EVT vs. $41-\mathrm{cm}^{3}$ medical therapy; $\left.P=0.19\right)$. The underlying explanation for this observation is unclear and certainly warrants further investigation given the dramatic benefit of EVT on functional outcomes. 
The results of DAWN and DEFUSE 3 are highly impactful since they will significantly alter the management and triage of patients previously thought to be "out of the window" for reperfusion therapy. In fact, the updated 2018 American Heart Association/American Stroke Association guidelines for management of anterior circulation LVO patients 6-24 h from LKW now recommend (level IA) obtaining CTP, DWI sequences or PWI to assist in patient selection for EVT (11). The findings of DAWN and DEFUSE 3 confirm that a subpopulation of LVO patients beyond $6 \mathrm{~h}$ from LKW with salvageable tissue, as evidenced by a clinical-ischemic core mismatch, that still benefit from EVT. In addition, while DAWN used CTP to determine the infarct core in a subset of patients, there was no core-perfusion mismatch requirement. There are, however, several additional findings from DAWN that merit discussion with regard to the overall generalizability of these findings. First, it is unknown how many patients were screened to enroll the 206 subjects reported in DAWN as screening logs were not collected. The discrepancy between the median NIHSS of 17 (interquartile range 13-21) in the EVT group but a median infarct volume of only $7.6 \mathrm{~cm}^{3}$ despite an LVO suggests a prolonged phase of penumbral survival and an opportunity to intervene may be present in more subjects than previously thought. These findings reinforce the critical role of collaterals in sustaining salvageable tissue until thrombolytic therapy is possible and affirm the inclusion criteria of ESCAPE. The poor outcomes seen in the medical arm of DEFUSE 3 and DAWN suggest that delayed collateral failure is common. The second important issue is how to generalize the results of DAWN and DEFUSE 3 to routine clinical practice. Future research should examine what additional subgroups of late-window LVO subjects can benefit from EVT. TENSION (Efficacy and safety of ThrombEctomy IN Stroke with extended lesion and extended time window) is one example of such a trial that plans to evaluate whether patients with severe strokes and large core volume (estimated by ASPECTS) can still have a relative benefit from EVT (122). TENSION is a prospective, open label, blinded endpoint, European randomized trial comparing the effectiveness of EVT in LVO patients with large infarcts (ASPECTS 3-5) up to $12 \mathrm{~h}$ or unknown LKW using an mRS ordinal analysis.

\section{REFERENCES}

1. Hacke W, Kaste M, Bluhmki E, Brozman M, Davalos A, Guidetti D, et al. Thrombolysis with alteplase 3 to 4.5 hours after acute ischemic stroke. N Engl J Med (2008) 359(13):1317-29. doi:10.1056/NEJMoa0804656

2. National Institute of Neurological Disorders and Stroke rt-PA Stroke Study Group. Tissue plasminogen activator for acute ischemic stroke. N Engl J Med (1995) 333(24):1581-7. doi:10.1056/NEJM199512143332401

3. Goyal M, Menon BK, van Zwam WH, Dippel DW, Mitchell PJ, Demchuk AM, et al. Endovascular thrombectomy after large-vessel ischaemic stroke: a meta-analysis of individual patient data from five randomised trials. Lancet (2016) 387(10029):1723-31. doi:10.1016/S0140-6736(16)00163-X

4. Saver JL, Goyal M, Bonafe A, Diener HC, Levy EI, Pereira VM, et al. Stentretriever thrombectomy after intravenous t-PA vs. t-PA alone in stroke. N Engl J Med (2015) 372(24):2285-95. doi:10.1056/NEJMoa1415061

5. Campbell BC, Mitchell PJ, Kleinig TJ, Dewey HM, Churilov L, Yassi N, et al. Endovascular therapy for ischemic stroke with perfusion-imaging selection. N Engl J Med (2015) 372(11):1009-18. doi:10.1056/NEJMoa1414792

\section{CONCLUSION}

The benefits of reperfusion therapies for acute ischemic stroke are well established for appropriately selected patients based on the duration of stroke symptoms. Neuroimaging-based methods of patient selection have, however, demonstrated the ability to identify additional populations of stroke patients that could benefit from late-window reperfusion therapy. Advanced neuroimaging techniques are both feasible and efficacious in the treatment allocation of SUSO patients based on either the presence of salvageable tissue on clinical-imaging mismatch or via a radiographic time-stamp of stroke duration. Going forward, with the anticipated results of several large Phase 3 trials, the management of this unique population of stroke patients will likely change for the better. Future research should continue to refine the approach to identifying additional populations of SUSO patients that would benefit from reperfusion therapy.

\section{AUTHOR CONTRIBUTIONS}

ME conceived the idea, drafted the manuscript, designed the figures, and provided critical review of the manuscript and figures. $\mathrm{AB}$ designed the figures, and provided critical review of the manuscript and figures. LS provided critical review of the manuscript and figures. OW conceived the idea, drafted the manuscript, designed the figures, and provided critical review of the manuscript and figures.

\section{FUNDING}

This research was carried out in part with support from the National Institutes of Health and NINDS Specialized Program of Transitional Research in Acute Stroke (SPOTRIAS) (grant number P50-NS051343) and at the Athinoula A. Martinos Center for Biomedical Imaging at the Massachusetts General Hospital, using resources provided by the Center for Functional Neuroimaging Technologies (grant number P41EB015896), a P41 Biotechnology Resource Grant supported by the National Institute of Biomedical Imaging and Bioengineering (NIBIB), National Institutes of Health.

6. Berkhemer OA, Fransen PS, Beumer D, van den Berg LA, Lingsma HF, Yoo AJ, et al. A randomized trial of intraarterial treatment for acute ischemic stroke. N Engl J Med (2015) 372(1):11-20. doi:10.1056/NEJMoa1411587

7. Albers GW, Marks MP, Kemp S, Christensen S, Tsai JP, Ortega-Gutierrez S, et al. Thrombectomy for stroke at 6 to 16 hours with selection by perfusion imaging. N Engl J Med (2018) 378(8):708-18. doi:10.1056/ NEJMoa1713973

8. Nogueira RG, Jadhav AP, Haussen DC, Bonafe A, Budzik RF, Bhuva P, et al. Thrombectomy 6 to 24 hours after stroke with a mismatch between deficit and infarct. N Engl J Med (2018) 378(1):11-21. doi:10.1056/NEJMoa1706442.

9. Jadhav AP, Desai SM, Kenmuir CL, Rocha M, Starr MT, Molyneaux BJ, et al. Eligibility for endovascular trial enrollment in the 6- to 24-hour time window: analysis of a single comprehensive stroke center. Stroke (2018) 49(4):1015-7. doi:10.1161/STROKEAHA.117.020273

10. Adeoye O, Hornung R, Khatri P, Kleindorfer D. Recombinant tissue-type plasminogen activator use for ischemic stroke in the United States: a doubling of treatment rates over the course of 5 years. Stroke (2011) 42(7):1952-5. doi:10.1161/STROKEAHA.110.612358 
11. Powers WJ, Rabinstein AA, Ackerson T, Adeoye OM, Bambakidis NC, Becker K, et al. 2018 guidelines for the early management of patients with acute ischemic stroke: a guideline for healthcare professionals from the American Heart Association/American Stroke Association. Stroke (2018) 49(3):e46-110. doi:10.1161/STR.0000000000000158

12. Maas MB, Singhal AB. Unwitnessed stroke: impact of different onset times on eligibility into stroke trials. J Stroke Cerebrovasc Dis (2013) 22(3):241-3. doi:10.1016/j.jstrokecerebrovasdis.2011.08.004

13. Kim YJ, Kim BJ, Kwon SU, Kim JS, Kang DW. Unclear-onset stroke: daytime-unwitnessed stroke vs. wake-up stroke. Int J Stroke (2016) 11(2):212-20. doi:10.1177/1747493015616513

14. Fink JN, Kumar S, Horkan C, Linfante I, Selim MH, Caplan LR, et al. The stroke patient who woke up: clinical and radiological features, including diffusion and perfusion MRI. Stroke (2002) 33(4):988-93. doi:10.1161/01. STR.0000014585.17714.67

15. Marler JR, Price TR, Clark GL, Muller JE, Robertson T, Mohr JP, et al. Morning increase in onset of ischemic stroke. Stroke (1989) 20(4):473-6. doi:10.1161/01.STR.20.4.473

16. Mackey J, Kleindorfer D, Sucharew H, Moomaw CJ, Kissela BM, Alwell K, et al. Population-based study of wake-up strokes. Neurology (2011) 76(19): 1662-7. doi:10.1212/WNL.0b013e318219fb30

17. Wu O, Schwamm LH, Sorensen AG. Imaging stroke patients with unclear onset times. Neuroimaging Clin N Am (2011) 21(2):327-44, xi. doi:10.1016/j. nic.2011.02.008

18. Chaturvedi S, Adams HP Jr, Woolson RF. Circadian variation in ischemic stroke subtypes. Stroke (1999) 30(9):1792-5. doi:10.1161/01.STR.30.9.1792

19. Serena J, Davalos A, Segura T, Mostacero E, Castillo J. Stroke on awakening: looking for a more rational management. Cerebrovasc Dis (2003) 16(2): 128-33. doi:10.1159/000070592

20. Lago A, Geffner D, Tembl J, Landete L, Valero C, Baquero M. Circadian variation in acute ischemic stroke: a hospital-based study. Stroke (1998) 29(9):1873-5. doi:10.1161/01.STR.29.9.1873

21. Argentino C, Toni D, Rasura M, Violi F, Sacchetti ML, Allegretta A, et al. Circadian variation in the frequency of ischemic stroke. Stroke (1990) 21(3):387-9. doi:10.1161/01.STR.21.3.387

22. Elliott WJ. Circadian variation in the timing of stroke onset: a meta-analysis. Stroke (1998) 29(5):992-6. doi:10.1161/01.STR.29.5.992

23. Andrews NP, Gralnick HR, Merryman P, Vail M, Quyyumi AA. Mechanisms underlying the morning increase in platelet aggregation: a flow cytometry study. J Am Coll Cardiol (1996) 28(7):1789-95. doi:10.1016/ S0735-1097(96)00398-1

24. Redon J. The normal circadian pattern of blood pressure: implications for treatment. Int J Clin Pract Suppl (2004) 145:3-8. doi:10.1111/j.1742-1241. 2004.00403.x

25. Scheer FA, Shea SA. Human circadian system causes a morning peak in prothrombotic plasminogen activator inhibitor-1 (PAI-1) independent of the sleep/wake cycle. Blood (2014) 123(4):590-3. doi:10.1182/blood-201307-517060

26. Todo K, Moriwaki H, Saito K, Tanaka M, Oe H, Naritomi H. Early CT findings in unknown-onset and wake-up strokes. Cerebrovasc Dis (2006) 21(5-6):367-71. doi:10.1159/000091545

27. Denny MC, Boehme AK, Dorsey AM, George AJ, Yeh AD, Albright KC, et al. Wake-up strokes are similar to known-onset morning strokes in severity and outcome. J Neurol Neurol Disord (2014) 1(1):102. doi:10.15744/ 2454-4981.1.102

28. Moradiya Y, Janjua N. Presentation and outcomes of "wake-up strokes" in a large randomized stroke trial: analysis of data from the international stroke trial. J Stroke Cerebrovasc Dis (2013) 22(8):e286-92. doi:10.1016/j. jstrokecerebrovasdis.2012.07.016

29. Reid JM, Dai D, Cheripelli B, Christian C, Reidy Y, Gubitz GJ, et al. Differences in wake-up and unknown onset stroke examined in a stroke registry. Int J Stroke (2015) 10(3):331-5. doi:10.1111/ijs.12388

30. Thomalla G, Boutitie F, Fiebach JB, Simonsen CZ, Nighoghossian N, Pedraza S, et al. Stroke with unknown time of symptom onset: baseline clinical and magnetic resonance imaging data of the first thousand patients in WAKE-UP (efficacy and safety of MRI-based thrombolysis in wake-up stroke: a randomized, doubleblind, placebo-controlled trial). Stroke (2017) 48(3):770-3. doi:10.1161/STROKEAHA.116.015233
31. Roveri L, La Gioia S, Ghidinelli C, Anzalone N, De Filippis C, Comi G. Wake-up stroke within 3 hours of symptom awareness: imaging and clinical features compared to standard recombinant tissue plasminogen activator treated stroke. J Stroke Cerebrovasc Dis (2013) 22(6):703-8. doi:10.1016/j. jstrokecerebrovasdis.2011.10.003

32. Costa R, Pinho J, Alves JN, Amorim JM, Ribeiro M, Ferreira C. Wake-up stroke and stroke within the therapeutic window for thrombolysis have similar clinical severity, imaging characteristics, and outcome. J Stroke Cerebrovasc Dis (2016) 25(3):511-4. doi:10.1016/j.jstrokecerebrovasdis.2015. 10.032

33. Huisa BN, Raman R, Ernstrom K, Tafreshi G, Stemer A, Meyer BC, et al. Alberta stroke program early CT score (ASPECTS) in patients with wake-up stroke. J Stroke Cerebrovasc Dis (2010) 19(6):475-9. doi:10.1016/j. jstrokecerebrovasdis.2010.03.003

34. Barber PA, Demchuk AM, Zhang J, Buchan AM. Validity and reliability of a quantitative computed tomography score in predicting outcome of hyperacute stroke before thrombolytic therapy. ASPECTS study group. Alberta stroke programme early CT score. Lancet (2000) 355(9216):1670-4. doi:10.1016/S0140-6736(00)02237-6

35. Silva GS, Lima FO, Camargo EC, Smith WS, Singhal AB, Greer DM, et al. Wake-up stroke: clinical and neuroimaging characteristics. Cerebrovasc Dis (2010) 29(4):336-42. doi:10.1159/000278929

36. Thomalla G, Rossbach P, Rosenkranz M, Siemonsen S, Krutzelmann A, Fiehler J, et al. Negative fluid-attenuated inversion recovery imaging identifies acute ischemic stroke at 3 hours or less. Ann Neurol (2009) 65(6):724-32. doi:10.1002/ana.21651

37. Petkova M, Rodrigo S, Lamy C, Oppenheim G, Touze E, Mas JL, et al. MR imaging helps predict time from symptom onset in patients with acute stroke: implications for patients with unknown onset time. Radiology (2010) 257(3):782-92. doi:10.1148/radiol.10100461

38. Aoki J, Kimura K, Iguchi Y, Shibazaki K, Sakai K, Iwanaga T. FLAIR can estimate the onset time in acute ischemic stroke patients. J Neurol Sci (2010) 293(1-2):39-44. doi:10.1016/j.jns.2010.03.011

39. Ebinger M, Galinovic I, Rozanski M, Brunecker P, Endres M, Fiebach JB. Fluid-attenuated inversion recovery evolution within 12 hours from stroke onset: a reliable tissue clock? Stroke (2010) 41(2):250-5. doi:10.1161/ STROKEAHA.109.568410

40. Legge J, Graham A, Male S, Copeland D, Lee R, Goyal N, et al. Fluid-attenuated inversion recovery (FLAIR) signal intensity can identify stroke within 6 and 8 hours. J Stroke Cerebrovasc Dis (2017) 26(7):1582-7. doi:10.1016/j. jstrokecerebrovasdis.2017.02.030

41. Thomalla G, Cheng B, Ebinger M, Hao Q, Tourdias T, Wu O, et al. DWIFLAIR mismatch for the identification of patients with acute ischaemic stroke within $4.5 \mathrm{~h}$ of symptom onset (PRE-FLAIR): a multicentre observational study. Lancet Neurol (2011) 10(11):978-86. doi:10.1016/S1474-4422(11) 70192-2

42. Emeriau S, Serre I, Toubas O, Pombourcq F, Oppenheim C, Pierot L. Can diffusion-weighted imaging-fluid-attenuated inversion recovery mismatch (positive diffusion-weighted imaging/negative fluid-attenuated inversion recovery) at 3 Tesla identify patients with stroke at $<4.5$ hours? Stroke (2013) 44(6):1647-51. doi:10.1161/STROKEAHA.113.001001

43. Nagai K, Aoki J, Sakamoto Y, Kimura K. About 30\% of wake-up stroke patients may be candidate for the tPA therapy using negative-FLAIR as a "tissue clock". J Neurol Sci (2017) 382:101-4. doi:10.1016/j.jns.2017.09.042

44. Saver JL. Time is brain--quantified. Stroke (2006) 37(1):263-6. doi:10.1161/ 01.STR.0000196957.55928.ab

45. Baird AE, Warach S. Magnetic resonance imaging of acute stroke. JCereb Blood Flow Metab (1998) 18(6):583-609. doi:10.1097/00004647-19980600000001

46. Broderick JP, Palesch YY, Demchuk AM, Yeatts SD, Khatri P, Hill MD, et al. Endovascular therapy after intravenous t-PA versus t-PA alone for stroke. N Engl J Med (2013) 368(10):893-903. doi:10.1056/NEJMoa1214300

47. Jovin TG, Chamorro A, Cobo E, de Miquel MA, Molina CA, Rovira A, et al. Thrombectomy within 8 hours after symptom onset in ischemic stroke. $N$ Engl J Med (2015) 372(24):2296-306. doi:10.1056/NEJMoa1503780

48. Goyal M, Demchuk AM, Menon BK, Eesa M, Rempel JL, Thornton J, et al. Randomized assessment of rapid endovascular treatment of ischemic stroke. N Engl J Med (2015) 372(11):1019-30. doi:10.1056/NEJMoa1414905 
49. Campbell BC, Purushotham A, Christensen S, Desmond PM, Nagakane Y, Parsons MW, et al. The infarct core is well represented by the acute diffusion lesion: sustained reversal is infrequent. JCereb Blood Flow Metab (2012) 32(1):50-6. doi:10.1038/jcbfm.2011.102

50. Wintermark M, Albers GW, Broderick JP, Demchuk AM, Fiebach JB, Fiehler J, et al. Acute stroke imaging research roadmap II. Stroke (2013) 44(9):2628-39. doi:10.1161/STROKEAHA.113.002015

51. Shih LC, Saver JL, Alger JR, Starkman S, Leary MC, Vinuela F, et al. Perfusion-weighted magnetic resonance imaging thresholds identifying core, irreversibly infarcted tissue. Stroke (2003) 34(6):1425-30. doi:10.1161/01. STR.0000072998.70087.E9

52. Sorensen AG, Buonanno FS, Gonzalez RG, Schwamm LH, Lev MH, HuangHellinger FR, et al. Hyperacute stroke: evaluation with combined multisection diffusion-weighted and hemodynamically weighted echo-planar MR imaging. Radiology (1996) 199(2):391-401. doi:10.1148/radiology.199.2. 8668784

53. Sorensen AG, Copen WA, Ostergaard L, Buonanno FS, Gonzalez RG, RordorfG, et al. Hyperacute stroke: simultaneous measurement of relative cerebral blood volume, relative cerebral blood flow, and mean tissue transit time. Radiology (1999) 210(2):519-27. doi:10.1148/radiology.210.2.r99fe06519

54. Warach S, Dashe JF, Edelman RR. Clinical outcome in ischemic stroke predicted by early diffusion-weighted and perfusion magnetic resonance imaging: a preliminary analysis. J Cereb Blood Flow Metab (1996) 16(1):53-9. doi:10.1097/00004647-199601000-00006

55. Wu O, Koroshetz WJ, Ostergaard L, Buonanno FS, Copen WA, Gonzalez RG, et al. Predicting tissue outcome in acute human cerebral ischemia using combined diffusion- and perfusion-weighted MR imaging. Stroke (2001) 32(4):933-42. doi:10.1161/01.STR.32.4.933

56. Wu O, Christensen S, Hjort N, Dijkhuizen RM, Kucinski T, Fiehler J, et al. Characterizing physiological heterogeneity of infarction risk in acute human ischaemic stroke using MRI. Brain (2006) 129(Pt 9):2384-93. doi:10.1093/ brain/awl183

57. Albers GW, Thijs VN, Wechsler L, Kemp S, Schlaug G, Skalabrin E, et al. Magnetic resonance imaging profiles predict clinical response to early reperfusion: the diffusion and perfusion imaging evaluation for understanding stroke evolution (DEFUSE) study. Ann Neurol (2006) 60(5):508-17. doi:10.1002/ana.20976

58. Lansberg MG, Straka M, Kemp S, Mlynash M, Wechsler LR, Jovin TG, et al. MRI profile and response to endovascular reperfusion after stroke (DEFUSE 2): a prospective cohort study. Lancet Neurol (2012) 11(10):860-7. doi:10.1016/S1474-4422(12)70203-X

59. Fiebach JB, Schellinger PD, Jansen O, Meyer M, Wilde P, Bender J, et al. CT and diffusion-weighted MR imaging in randomized order: diffusion-weighted imaging results in higher accuracy and lower interrater variability in the diagnosis of hyperacute ischemic stroke. Stroke (2002) 33(9):2206-10. doi:10.1161/01.STR.0000026864.20339.CB

60. Copen WA, Yoo AJ, Rost NS, Morais LT, Schaefer PW, González RG, et al. In patients with suspected acute stroke, CT perfusion-based cerebral blood flow maps cannot substitute for DWI in measuring the ischemic core. PLoS One (2017) 12(11):e0188891. doi:10.1371/journal.pone.0188891

61. Boned S, Padroni M, Rubiera M, Tomasello A, Coscojuela P, Romero N, et al. Admission CT perfusion may overestimate initial infarct core: the ghost infarct core concept. J Neurointerv Surg (2017) 9(1):66-9. doi:10.1136/ neurintsurg-2016-012494

62. Lui YW, Tang ER, Allmendinger AM, Spektor V. Evaluation of CT perfusion in the setting of cerebral ischemia: patterns and pitfalls. AJNR Am J Neuroradiol (2010) 31(9):1552-63. doi:10.3174/ajnr.A2026

63. Wintermark M, Reichhart M, Cuisenaire O, Maeder P, Thiran JP, Schnyder P, et al. Comparison of admission perfusion computed tomography and qualitative diffusion- and perfusion-weighted magnetic resonance imaging in acute stroke patients. Stroke (2002) 33(8):2025-31. doi:10.1161/01. STR.0000023579.61630.AC

64. Wintermark M, Reichhart M, Thiran JP, Maeder P, Chalaron M, Schnyder P, et al. Prognostic accuracy of cerebral blood flow measurement by perfusion computed tomography, at the time of emergency room admission, in acute stroke patients. Ann Neurol (2002) 51(4):417-32. doi:10.1002/ana.10136

65. Wintermark M, Flanders AE, Velthuis B, Meuli R, van Leeuwen M, Goldsher D, et al. Perfusion-CT assessment of infarct core and penumbra: receiver operating characteristic curve analysis in 130 patients suspected of acute hemispheric stroke. Stroke (2006) 37(4):979-85. doi:10.1161/01. STR.0000209238.61459.39

66. Abdelgawad EA, Higazi MM, Abdelbaky AO, Abdelghany HS. Diagnostic performance of CT cerebral blood volume colour maps for evaluation of acute infarcts; comparison with diffusion-weighted MRI within 12hours of major stroke onset. J Neuroradiol (2017) 44(1):10-6. doi:10.1016/j.neurad. 2016.10.005

67. Campbell BC, Christensen S, Levi CR, Desmond PM, Donnan GA, Davis SM, et al. Cerebral blood flow is the optimal CT perfusion parameter for assessing infarct core. Stroke (2011) 42(12):3435-40. doi:10.1161/STROKEAHA. 111.618355

68. Deipolyi AR, Wu O, Macklin EA, Schaefer PW, Schwamm LH, Gilberto Gonzalez R, et al. Reliability of cerebral blood volume maps as a substitute for diffusion-weighted imaging in acute ischemic stroke. J Magn Reson Imaging (2012) 36(5):1083-7. doi:10.1002/jmri.23740

69. Geuskens RR, Borst J, Lucas M, Boers AM, Berkhemer OA, Roos YB, et al. Characteristics of misclassified CT perfusion ischemic core in patients with acute ischemic stroke. PLoS One (2015) 10(11):e0141571. doi:10.1371/journal. pone. 0141571

70. Schaefer PW, Souza L, Kamalian S, Hirsch JA, Yoo AJ, Gonzalez RG, et al. Limited reliability of computed tomographic perfusion acute infarct volume measurements compared with diffusion-weighted imaging in anterior circulation stroke. Stroke (2015) 46(2):419-24. doi:10.1161/STROKEAHA. 114.007117

71. Copen WA, Morais LT, Wu O, Schwamm LH, Schaefer PW, González RG, et al. In acute stroke, can CT perfusion-derived cerebral blood volume maps substitute for diffusion-weighted imaging in identifying the ischemic core? PLoS One (2015) 10(7):e0133566. doi:10.1371/journal.pone.0133566

72. Mishra NK, Christensen S, Wouters A, Campbell BC, Straka M, Mlynash M, et al. Reperfusion of very low cerebral blood volume lesion predicts parenchymal hematoma after endovascular therapy. Stroke (2015) 46(5):1245-9. doi:10.1161/STROKEAHA.114.008171

73. Alsop DC, Makovetskaya E, Kumar S, Selim M, Schlaug G. Markedly reduced apparent blood volume on bolus contrast magnetic resonance imaging as a predictor of hemorrhage after thrombolytic therapy for acute ischemic stroke. Stroke (2005) 36(4):746-50. doi:10.1161/01.STR.0000158913.91058.93

74. Hermitte L, Cho TH, Ozenne B, Nighoghossian N, Mikkelsen IK, Ribe L, et al. Very low cerebral blood volume predicts parenchymal hematoma in acute ischemic stroke. Stroke (2013) 44(8):2318-20. doi:10.1161/ STROKEAHA.113.001751

75. Campbell BC, Christensen S, Butcher KS, Gordon I, Parsons MW, Desmond PM, et al. Regional very low cerebral blood volume predicts hemorrhagic transformation better than diffusion-weighted imaging volume and thresholded apparent diffusion coefficient in acute ischemic stroke. Stroke (2010) 41(1):82-8. doi:10.1161/STROKEAHA.109.562116

76. Protto S, Pienimäki JP, Seppänen J, Numminen H, Sillanpää N. Low cerebral blood volume identifies poor outcome in stent retriever thrombectomy. Cardiovasc Intervent Radiol (2017) 40(4):502-9. doi:10.1007/s00270-016$1532-\mathrm{x}$

77. Tsogkas I, Knauth M, Schregel K, Behme D, Wasser K, Maier I, et al. Added value of CT perfusion compared to CT angiography in predicting clinical outcomes of stroke patients treated with mechanical thrombectomy. Eur Radiol (2016) 26(11):4213-9. doi:10.1007/s00330-016-4257-y

78. Hacke W, Albers G, Al-Rawi Y, Bogousslavsky J, Davalos A, Eliasziw M, et al. The Desmoteplase in Acute Ischemic Stroke Trial (DIAS): a phase II MRI-based 9-hour window acute stroke thrombolysis trial with intravenous desmoteplase. Stroke (2005) 36(1):66-73. doi:10.1161/01.STR. $0000149938.08731 .2 \mathrm{c}$

79. Hacke W, Furlan AJ, Al-Rawi Y, Davalos A, Fiebach JB, Gruber F, et al. Intravenous desmoteplase in patients with acute ischaemic stroke selected by MRI perfusion-diffusion weighted imaging or perfusion CT (DIAS-2): a prospective, randomised, double-blind, placebo-controlled study. Lancet Neurol (2009) 8(2):141-50. doi:10.1016/S1474-4422(08)70267-9

80. Furlan AJ, Eyding D, Albers GW, Al-Rawi Y, Lees KR, Rowley HA, et al. Dose escalation of Desmoteplase for Acute Ischemic Stroke (DEDAS): evidence of safety and efficacy 3 to 9 hours after stroke onset. Stroke (2006) 37(5):1227-31. doi:10.1161/01.STR.0000217403.66996.6d

81. Fiebach JB, Al-Rawi Y, Wintermark M, Furlan AJ, Rowley HA, Lindstén A, et al. Vascular occlusion enables selecting acute ischemic stroke patients 
for treatment with desmoteplase. Stroke (2012) 43(6):1561-6. doi:10.1161/ STROKEAHA.111.642322

82. Albers GW, von Kummer R, Truelsen T, Jensen JK, Ravn GM, Grønning BA, et al. Safety and efficacy of desmoteplase given 3-9 h after ischaemic stroke in patients with occlusion or high-grade stenosis in major cerebral arteries (DIAS-3): a double-blind, randomised, placebo-controlled phase 3 trial. Lancet Neurol (2015) 14(6):575-84. doi:10.1016/S1474-4422(15)00047-2

83. von Kummer R, Mori E, Truelsen T, Jensen JS, Grønning BA, Fiebach JB, et al. Desmoteplase 3 to 9 hours after major artery occlusion stroke: the DIAS-4 trial (efficacy and safety study of desmoteplase to treat acute ischemic stroke). Stroke (2016) 47(12):2880-7. doi:10.1161/STROKEAHA.116. 013715

84. Davis SM, Donnan GA, Parsons MW, LeviC, Butcher KS, Peeters A, etal. Effects of alteplase beyond $3 \mathrm{~h}$ after stroke in the Echoplanar Imaging Thrombolytic Evaluation trial (EPITHET): a placebo-controlled randomised trial. Lancet Neurol (2008) 7(4):299-309. doi:10.1016/S1474-4422(08)70044-9

85. Nagakane Y, Christensen S, Brekenfeld C, Ma H, Churilov L, Parsons MW, et al. EPITHET: positive result after reanalysis using baseline diffusionweighted imaging/perfusion-weighted imaging co-registration. Stroke (2011) 42(1):59-64. doi:10.1161/STROKEAHA.110.580464

86. Parsons M, Spratt N, Bivard A, Campbell B, Chung K, Miteff F, et al. A randomized trial of tenecteplase versus alteplase for acute ischemic stroke. N Engl J Med (2012) 366(12):1099-107. doi:10.1056/NEJMoa1109842

87. Logallo N, Novotny V, Assmus J, Kvistad CE, Alteheld L, Ronning OM, et al. Tenecteplase versus alteplase for management of acute ischaemic stroke (NOR-TEST): a phase 3, randomised, open-label, blinded endpoint trial. Lancet Neurol (2017) 16(10):781-8. doi:10.1016/S1474-4422(17)30253-3

88. Tenecteplase in Wake-Up Ischaemic Stroke Trial. Available from: https:// ClinicalTrials.gov/show/NCT03181360 (Accessed: February 15, 2018).

89. Kidwell CS, Jahan R, Gornbein J, Alger JR, Nenov V, Ajani Z, et al. A trial of imaging selection and endovascular treatment for ischemic stroke. $N$ Engl J Med (2013) 368(10):914-23. doi:10.1056/NEJMoa1212793

90. Kidwell CS, Wintermark M, De Silva DA, Schaewe TJ, Jahan R, Starkman S, et al. Multiparametric MRI and CT models of infarct core and favorable penumbral imaging patterns in acute ischemic stroke. Stroke (2013) 44(1):73-9. doi:10.1161/STROKEAHA.112.670034

91. Dávalos A, Blanco M, Pedraza S, Leira R, Castellanos M, Pumar JM, et al. The clinical-DWI mismatch: a new diagnostic approach to the brain tissue at risk of infarction. Neurology (2004) 62(12):2187-92. doi:10.1212/01.WNL. 0000130570.41127.EA

92. Tei H, Uchiyama S, Usui T. Clinical-diffusion mismatch defined by NIHSS and ASPECTS in non-lacunar anterior circulation infarction. J Neurol (2007) 254(3):340-6. doi:10.1007/s00415-006-0368-8

93. Prosser J, Butcher K, Allport L, Parsons M, MacGregor L, Desmond P, et al. Clinical-diffusion mismatch predicts the putative penumbra with high specificity. Stroke (2005) 36(8):1700-4. doi:10.1161/01.STR.0000173407.40773.17

94. Lansberg MG, Thijs VN, Hamilton S, Schlaug G, Bammer R, Kemp S, et al. Evaluation of the clinical-diffusion and perfusion-diffusion mismatch models in DEFUSE. Stroke (2007) 38(6):1826-30. doi:10.1161/ STROKEAHA.106.480145

95. Ebinger M, Iwanaga T, Prosser JF, De Silva DA, Christensen S, Collins M, et al. Clinical-diffusion mismatch and benefit from thrombolysis 3 to 6 hours after acute stroke. Stroke (2009) 40(7):2572-4. doi:10.1161/ STROKEAHA.109.548073

96. Nogueira RG, Kemmling A, Souza LM, Payabvash S, Hirsch JA, Yoo AJ, et al. Clinical diffusion mismatch better discriminates infarct growth than mean transit time-diffusion weighted imaging mismatch in patients with middle cerebral artery-M1 occlusion and limited infarct core. J Neurointerv Surg (2017) 9(2):127-30. doi:10.1136/neurintsurg-2014-011602

97. Messé SR, Kasner SE, Chalela JA, Cucchiara B, Demchuk AM, Hill MD, et al. CT-NIHSS mismatch does not correlate with MRI diffusion-perfusion mismatch. Stroke (2007) 38(7):2079-84. doi:10.1161/STROKEAHA.106.480731

98. Kent DM, Hill MD, Ruthazer R, Coutts SB, Demchuk AM, Dzialowski I, et al. "Clinical-CT mismatch" and the response to systemic thrombolytic therapy in acute ischemic stroke. Stroke (2005) 36(8):1695-9. doi:10.1161/01. STR.0000173397.31469.4b

99. Boxerman JL, Jayaraman MV, Mehan WA, Rogg JM, Haas RA. Clinical stroke penumbra: use of National Institutes Of Health Stroke Scale as a surrogate for CT perfusion in patient triage for intra-arterial middle cerebral artery stroke therapy. AJNR Am J Neuroradiol (2012) 33(10):1893-900. doi:10.3174/ ajnr.A3102

100. Souza LC, Yoo AJ, Chaudhry ZA, Payabvash S, Kemmling A, Schaefer PW, et al. Malignant CTA collateral profile is highly specific for large admission DWI infarct core and poor outcome in acute stroke. AJNR Am J Neuroradiol (2012) 33(7):1331-6. doi:10.3174/ajnr.A2985

101. Vagal A, Menon BK, Foster LD, Livorine A, Yeatts SD, Qazi E, et al. Association between CT angiogram collaterals and CT perfusion in the interventional management of stroke III trial. Stroke (2016) 47(2):535-8. doi:10.1161/STROKEAHA.115.011461

102. Liebeskind DS, Tomsick TA, Foster LD, Yeatts SD, Carrozzella J, Demchuk AM, et al. Collaterals at angiography and outcomes in the interventional management of stroke (IMS) III trial. Stroke (2014) 45(3):759-64. doi:10.1161/ STROKEAHA.113.004072

103. Marks MP, Lansberg MG, Mlynash M, Olivot JM, Straka M, Kemp S, et al. Effect of collateral blood flow on patients undergoing endovascular therapy for acute ischemic stroke. Stroke (2014) 45(4):1035-9. doi:10.1161/ STROKEAHA.113.004085

104. Kawano H, Bivard A, Lin L, Spratt NJ, Miteff F, Parsons MW, et al. Relationship between collateral status, contrast transit, and contrast density in acute ischemic stroke. Stroke (2016) 47(3):742-9. doi:10.1161/STROKEAHA. 115.011320

105. Cho AH, Sohn SI, Han MK, Lee DH, Kim JS, Choi CG, et al. Safety and efficacy of MRI-based thrombolysis in unclear-onset stroke. A preliminary report. Cerebrovasc Dis (2008) 25(6):572-9. doi:10.1159/000132204

106. Barreto AD, Martin-Schild S, Hallevi H, Morales MM, Abraham AT, Gonzales NR, et al. Thrombolytic therapy for patients who wake-up with stroke. Stroke (2009) 40(3):827-32. doi:10.1161/STROKEAHA.108. 528034

107. Manawadu D, Bodla S, Jarosz J, Keep J, Kalra L. A case-controlled comparison of thrombolysis outcomes between wake-up and known time of onset ischemic stroke patients. Stroke (2013) 44(8):2226-31. doi:10.1161/ STROKEAHA.112.673145

108. Natarajan SK, Karmon Y, Snyder KV, Ohta H, Hauck EF, Hopkins LN, et al. Prospective acute ischemic stroke outcomes after endovascular therapy: a real-world experience. World Neurosurg (2010) 74(4-5):455-64. doi:10.1016/j.wneu.2010.06.035

109. Aghaebrahim A, Leiva-Salinas C, Jadhav AP, Jankowitz B, Zaidi S, Jumaa M, et al. Outcomes after endovascular treatment for anterior circulation stroke presenting as wake-up strokes are not different than those with witnessed onset beyond 8 hours. J Neurointerv Surg (2015) 7(12):875-80. doi:10.1136/ neurintsurg-2014-011316

110. Jovin TG, Liebeskind DS, Gupta R, Rymer M, Rai A, Zaidat OO, et al. Imagingbased endovascular therapy for acute ischemic stroke due to proximal intracranial anterior circulation occlusion treated beyond 8 hours from time last seen well: retrospective multicenter analysis of 237 consecutive patients. Stroke (2011) 42(8):2206-11. doi:10.1161/STROKEAHA.110.604223

111. Ribo M, Flores A, Rubiera M, Pagola J, Sargento-Freitas J, Rodriguez-Luna D, et al. Extending the time window for endovascular procedures according to collateral pial circulation. Stroke (2011) 42(12):3465-9. doi:10.1161/ STROKEAHA.111.623827

112. Hwang YH, Kang DH, Kim YW, Kim YS, Park SP, Liebeskind DS. Impact of time-to-reperfusion on outcome in patients with poor collaterals. AJNR Am J Neuroradiol (2015) 36(3):495-500. doi:10.3174/ajnr.A4151

113. Adams HP Jr, Effron MB, Torner J, Davalos A, Frayne J, Teal P, et al. Emergency administration of abciximab for treatment of patients with acute ischemic stroke: results of an international phase III trial: abciximab in emergency treatment of stroke trial (AbESTT-II). Stroke (2008) 39(1):87-99. doi:10.1161/STROKEAHA.106.476648

114. Adams HP Jr, Leira EC, Torner JC, Barnathan E, Padgett L, Effron MB, et al. Treating patients with 'wake-up' stroke: the experience of the AbESTT-II trial. Stroke (2008) 39(12):3277-82. doi:10.1161/STROKEAHA.107.508853

115. Barreto AD, Fanale CV, Alexandrov AV, Gaffney KC, Vahidy FS, Nguyen CB, et al. Prospective, open-label safety study of intravenous recombinant tissue plasminogen activator in wake-up stroke. Ann Neurol (2016) 80(2):211-8. doi:10.1002/ana.24700

116. ClinicalTrials.gov. Safety of Intravenous Thrombolytics in Stroke on Awakening. Available from: https://ClinicalTrials.gov/show/NCT01643902 (Accessed: February 15, 2018). 
117. Kang DW, Sohn SI, Hong KS, Yu KH, Hwang YH, Han MK, et al. Reperfusion therapy in unclear-onset stroke based on MRI evaluation (RESTORE): a prospective multicenter study. Stroke (2012) 43(12):3278-83. doi:10.1161/ STROKEAHA.112.675926

118. Aoki J, Kimura K, Iguchi Y, Shibazaki K, Iwanaga T, Watanabe M, et al. Intravenous thrombolysis based on diffusion-weighted imaging and fluidattenuated inversion recovery mismatch in acute stroke patients with unknown onset time. Cerebrovasc Dis (2011) 31(5):435-41. doi:10.1159/000323850

119. Schwamm LH, Wu O, Song SS, Latour LL, Ford AL, Hsia A, et al. Intravenous thrombolysis in unwitnessed stroke onset: MR WITNESS trial results. Ann Neurol (2018). doi:10.1002/ana.25235

120. Koga M, Toyoda K, Kimura K, Yamamoto H, Sasaki M, Hamasaki T, et al. THrombolysis for acute wake-up and unclear-onset strokes with alteplase at $0.6 \mathrm{mg} / \mathrm{kg}$ (THAWS) trial. Int J Stroke (2014) 9(8):1117-24. doi:10.1111/ ijs. 12360

121. Ma H, Parsons MW, Christensen S, Campbell BC, Churilov L, Connelly A, et al. A multicentre, randomized, double-blinded, placebo-controlled Phase III study to investigate extending the time for thrombolysis in emergency neurological deficits (EXTEND). Int J Stroke (2012) 7(1):74-80. doi:10.1111/ j.1747-4949.2011.00730.x

122. ClinicalTrials.gov. Efficacy and Safety of Thrombectomy in Stroke With Extended Lesion and Extended Time Window. Available from: https:// ClinicalTrials.gov/show/NCT03094715 (Accessed: February 15, 2018).

Conflict of Interest Statement: ME reports no disclosures. OW is the co-inventor of a patent on Delay-compensated calculation of tissue blood flow, US Patent
7,512,435. 31 March 2009, and the patent has been licensed to General Electric Siemens, Imaging Biometrics and Olea Medical, consultant to Penumbra on topics unrelated to the article. OW and LS report being the principal investigator of an investigator-initiated study of extended-window intravenous thrombolysis funded by the National Institutes of Neurological Disorders and Stroke (clinicaltrials.gov/ show/NCT01282242) for which Genentech provides alteplase free of charge to Massachusetts General Hospital as well as supplemental per-patient payments to participating sites. LS reports serving as chair of the AHA/ASA GWTG stroke clinical work group and hospital accreditation Science Committee; serving as a stroke systems consultant to the Massachusetts Department of Public Health; and serving as a scientific consultant to LifeImage regarding user interface design and usability, and regarding trial design and conduct to Lundbeck (international steering committee, DIAS3, 4 trial), Penumbra (data and safety monitoring committee, Separator 3D and MIND trials) and Medtronic (Victory AF and Stroke AF trials). $\mathrm{AB}$ reports that the Wake-up Stroke study was partially supported by Genentech Inc., which provided study medication without charge as well as an investigator initiated grant to another investigator for monetary support of enrollment and pharmacy fees.

Copyright (C) 2018 Etherton, Barreto, Schwamm and Wu. This is an open-access article distributed under the terms of the Creative Commons Attribution License (CC BY). The use, distribution or reproduction in other forums is permitted, provided the original author(s) and the copyright owner are credited and that the original publication in this journal is cited, in accordance with accepted academic practice. No use, distribution or reproduction is permitted which does not comply with these terms. 